\title{
Venerische Krankheiten.
}

\author{
(Redigirt von Prof. Neisser in Breslau.)
}

\section{Gonorrhöe und deren Complicationen.}

1. Legrain Émile. Recherches sur les rapports qu'affecte le gonococcus avec les éléments du pus blennorrhagique. - Arch. de physiologie, 15. Août 1887.

2. Giovanni. Microbes de la blennorrhagie uréthrale de l'homme. - Union medic., 9. Décembre 1886.

3. Orcel. Persistance du gonococcus dans l'urèthre après la miction et le lavage de l'avant-canal. - Lyou médic., 4. IX. 1887.

4. Denti S. Sull' infettività della blenorragia. - Giorn. ital. delle mal. ven. e della pelle 1887,4 .

5. Bories. Manifestation nouvelle de l'infection blennorrhagique. - La semaine médic. 1887, $\mathrm{Nr}$. 40.

6. Bockhart M. Ueber secundäre Infection (Mischinfection) bei Harnröhrentripper. - Monatsh. f. prakt. Derm. 1887, Nr. 19.

7. Bumm E. Ueber gonorrhoische Mischinfectionen bein Weibe. - Deutsche med. Wochenschr. 1887, Nr. 49, pag. 1057.

8. Noeggerath E. Ueber latente und chronische Gonorrhöe beim weiblichen Geschlecht. - Deutsche med. Wochenschr. 1887, Nr. 49, pag. 1059.

9. Levy Fr. La gonorrhée latente chez la femme. - Hospitals Tidende (Copenhague) Nr. 1, 2, 3, 1887.

10. Prettyman S. Gouorrhoea in young children. - Medical Record Vol. 32, Nov. 12.1887.

11. Abaly $W$. C. Boracic acid in gonorrhoea.

12. Blane P. Quelques points du traitement de la blennorrhagie. - Prov. médic. $\mathrm{Nr}$. 44, 1887 .

13. Ledetsch. Ueber Chinin-Injectionen bei Gonorrhöe. - Prager med. Wochenschr.; Breslauer ärztl. Zeitschr.

14. Currier Andrew F. The abortive treatment of Gonorrhoea. - NewYork med. Journ., 29. Oct. 1887.

15. Rose $A$. The abortive treatment of Gonorrhoea. - New-York med. Journ., 8. und 22. Oct. 1887.

16. Osborne 0. T. (New-Haven, Conn.) The abortive treatment of Gonorrhoea. - New-York med. Journ. 1887, Nr. 15, pag. 401. 
17. Otramare Dr. (Geneve.) Les injections et In propagation de la blennorrhagie à lurèthre postérieur. - Rerue de la suisse romane, Octobre 1886.

18. Rand. The treatment of urethral inflammation in the male. - NewYork med. Journ., 3. Dec. 1887.

49. Sperling. Znr Sondentherapie der Harnröhe. - Therapent. Monatsh 1887, Nr. 7.

20. Casper. Dic Salbensonden bei Behandlungr der ehronischen Gonnrrhöe. - Therapent. Monatsh. 1857. Nr. 8.

21. Sperling. Zur Salbensondenbehandlung der Harnrïhr.. - Therapent. Monatsh. 1887, $\mathrm{Nr} .9$.

2.. Tommasoli. L'iniettore uretrale d'unguenti. - Giom, ital, delle mal. ven. e della pelle 1887, 5 .

23. Petersen 0. Der Urethral-Irrigator. - Monatsh. f. prakt. Derm. 188\%, Nr. 20, pag. 906.

24. Lohnstein. Ein never Spülapparat der Harnröhre. - Berl. klin. Wochenschr. 1887, 47.

20̈. Groeningen. Tripperbehandlung mittelst Spülkatheter. - Berl. klin. Wochenschr. 1887, อ̈1.

26. Schiitz J. Ein neuer elektrischer Apparat (Diaphotoskop) zn medicinischen Beleuchtungszwecken, insbesondere zur bequemen Frhellung des endoskopischen Gesichtsfeldes. - Monatsh. f. prakt. Derm. 1887, N. 20, pag. 899 .

27. Allen. Cases of Urethral-Endoscopy. - The Boston Medic. and surgic. Journ., 1. Dec. 1887, Vol. CXVII Nr. 22.

28. Friedrich L. L. (Washington). Vortrag in der "Medicnl society of the district of Columbia" vom 20. April 1887 über "Endoskopie“. Journ. of the Medic. Association, Chicago 1887, Nr. 10, pag. 31 ..

29. Belfleld. Sudden death after urethral injection. - The Journ. of the americ. medic. associat., 3. Dec. 1887.

30. Lavanx. Antisepsie de la vessie et de l'urèthre. Applications an traitement des rétrécissements. - Le Bullet. médic. 1857, Nr. 70, pag. 1117.

31. Hartmann. Des cystites douloureuses. - Thise, l'aris 1837.

32. Denny. (Case of stricture of the urethra; divulsion and cure.) Ein Fall von Strictur der Harnoohre; deren Sprengung und Heilung. Northwestern Lancet 1887, Nr. 3 .

33. Distin.Maddock E. A new urethral instrument. - Lancet $1887, \mathrm{Nr}$. 3347 , pag. 816.

34. Morton Edwin (Newark, England). The treatment of stricture of the urethra and urinary penile and serotal and perineal fistulae by electrolysis. - Brit. Med. Jonrn. 1887, Nr. 1396, pig. 711.

30. Nowman Robert. Synopsis of the second hundred cases of stricture of the urethra treated by electrolysis. - The Journ. of the americ. med. associat., Nr. 13 and 14, 1887.

36. Desnos. Rétrécissement du rectum consécutif à un abè̀s de la Prostate. - Gaz. médic. 1887, Nr. 50.

37. Wilson A. H. The prostate gland. A Review of its anatomy, pathology and treatment. - The Journ. of the americ. med. associat., $\mathrm{Nr}$. 15, 1887.

38. Fenwick E. Henry. Ueber Thonabdrücke der Prostata an Lebenden. - Langenbeck's Arch., XXXVI, 2.

39. Newmau. The treatment of enlarged prostate. - Brit. Med. Journ, 1. Oct. 1887.

40. Thompson F. Der hohe Blasenschnitt bei Prostatahypertrophie. Brit. Hed. Journ., Nr. 1403, 19. Nov. 1887, pag. 1103. 
41. Thacher. Periurethral-Abscess. The med. Record, New-York 1887, Nr. 887.

42. Montaz M. (Grenoble.) D'un mode fréquent et non décrit de l'orchiépididymite tuberculeuse aiguë. - Semaine médic. 1887, Nr. 41.

43. Kadler L. Schmerzlose Entfernung von spitzen Condylomen. - Medycyna 1887, Nr. 63.

44. Falcone Tebaldo, Per la patogenesi del reumatismo articolare. - Giorn. ital. delle mal. ven. e della pelle 1887, 4.

45. Aubert. Absence de gonococci dans l'arthrite blennorrhagique. - Le Bullet. médic. 1887, Nr. 50 .

46. Wagner. Ueber die Elektrotherapie der Spermatorrhöe. - Berl. klin. Wochenschr. 1887, Nr. 51.

47. Behandlung der Impotenz. - The international medical and surgical Synopsis, Vol. 1., Nr. 2. Oct.

48. Stewart $\mathrm{S}$. Congenitale Phimose. - The Journ. of the americ. medic. associat.

Legrain (1) bespricht die Eigenthümlichkeiten des Secrets bei acuter Gonorrhïe. Von der Mitte des zweiten Tages an constatirt er eine Abnahme der Epithelzellen, eine langsame Zunahme der Eiterzellen. Von hundert Leukocyten enthalten zwei bis drei Gonococcen. Diese wenigen Elemente liegen dicht aneinander gedrängt, umgeben von Gruppen intacter Zellenmassen. Die Zahl der Mikroben in den einzelnen Elementen ist verschieden; die eine Zelle enthält $\mathbf{z w o ̈ l f}$, eine andere $\mathbf{z w a n z i g , ~ e i n e ~ d r i t t e ~}$ achtzig Gonococcen. Die Cocceninvasion der Zellen geschieht zu verschiedenen Zeiten. Die Propagation der Coccen findet statt in der Contiguität der Zellen; sie dringt vom zweiten Tage an von der Schleimhautoberfläche in die Tiefe des Gewebes ein. Die Zahl der Eiterzellen nimmt im weiteren Verlaufe ausserordentlich zu; die der Epithelien schwindet. Auf der Hühe des acnten Stadiums ist ron fünf Leukocyten ciner mit Gonococcen behaftet. Das Vorkommen freier Gonococcen leugnet Legrain zwar nicht; jadoch sah er sie nur vereinzelt, niemals in grösseren Haufen. Die Vermehrung der Coccen geschieht intracellulär. Im subacuten Stadium sieht man wieder mehr Epithelzellen mit gequollenem Kern, der mehrere Vacnolen enthält. Coccenhältig sind die Epithelien jetzt nur selten. Der Zahl nach verhalten sie sich zu den Leukocyten wie 1:8 oder wie 1:10. Im chronischen Stadium dominiren an Zahl die desquamirten und coccentragenden Epithelien. Vereinzelte Gonococcen sieht man vielfach frei. Exacerbirt ein chronischer Tripper, so sieht man zuweilen massenhafte Eiterzellen ohne Gonococcen. Die Epithelien sind oft mit Gonococcen glejchsam überschwemmt. Die Localisation der Erkrankung ist jetzt zum zweiten Male auf der Schleimhautoberfläche. Die verschiedenen Grössenverhältnisse der Mikroben in demselken Secret erklürt Legrain durch ein verschiedenes Verhalten gegen Farbstoffe. Die Coccen in der Tiefe der Zellen und Kerne unterliegen der Tinction schwerer. Der Unterschied gleicht sich aus, wenn man das überaus schnell färbende Carbolfuchsin wählt. Es soll ferner nicht gleichgiltig sein, ob die Coccen im oberen Niveau des Präparats, oder in der Tiefe unmittelbar auf dem Objectträger gelegen sind. Die Tinclionsfähigkeit der Zellkerne nimmt ab unter dem Einflusse der in ihnen eingeschlossenen Gonoeoccen. Hier sieht man die letzteren von einer transparenten Zone umgeben. Diese aber ist ein Ansdruck für die Consumption tinctionsfühiger Substanz durch die Mikroben. Die Kernmasse lockert sich, sie erfüllt fast den ganzen Zellenleib. Das Protoplasma sieht man in hin und wieder nur spärlichen Mengen zusammengedrängt an den Polen der Zelle. Die Zelle scheint schliesslich nur aus Coccen za bestehen. Die Contouren der Zelle persistiren. Die Zelle selbst 
kann an Ausdehnung gewinnen. Man hat wohl ein Pecht, den Gonococen einen Einfluss auf die nutritiven Eigenschaften der Zellen zuzuschreiben. Im chronischen Stadium scheint die Vitalität des Gonococcus abzunehmen, sowie sein Näbrboden erscböpft wird. Impfungen ron Legrain (aus Culturversuchen) erzielten nur schwache Resultate.

Giovanni (2) behauptet: Aus dem gonorrhoischen Eiter des Mannes lassen sich fünf Mikroorganismen isoliren, welche differiren sowohl in morphologischer Beziehung als in den Culturen. Zwei Varietaiten sind mit denjeuigen identisch, welche sich in der nomalen männlichen Harnröhre finden lassen: Keines dieser Gebilde gleicht denjenigen, welche die ammoniakalische Gährung im Harne hervorruft. Impfungen unter die Haut, in das Peritoneum von Meerschweinchen liessen einen pyogenen Charakter nicht erkennen. Keiner dieser Mikroorganismen vermochte in der menschlichen Urethra eine Blennorrhïe zu erzengen. Die Reinculturen misslangen; dieser negative Erfolg schliesst aber die pathogene Bedentung des Gonococcus nicht aus; er lässt vielmehr nur die Unzulänglichkeit unserer Hilfsmittel für Culturen erkennen.

Orcel (3) behauptet: Der Gonococcus sitat nicht nur im Eiter, sondern auch in den Geweben selbst. Schabt man die Urethralschleimhaut mit einer 2-3 Ctm. tief eingeführten Horncurette ab. so gelingt der Nachweis. selbst wenn der Kranke zuvor urinirte oder eine Injection empfing. Un den hinteren Harnröhrenabschnitt zu schützen, soll man nur geringe Mengen unter schwachem Drucke injiciren. Die Urinentleerung vor der Einspritzung reinigt erstens die Harmröhre; $\mathbf{z w e i t e n s}$ macht sie die Schleimhaut in der Folge viel empfänglicher für die medicamentöse Einwirkung; drittens lässt sie einen länger andanernden Contact zu. In den Präparaten, welche Orcel nit der Curette bereitete, sah er die Coccen niemals in Zellen, vielmehr stets frei, sei es zerstreut, sei es in Gruppen.

Friedheim.

Denti (4) unterscheidet erstens eine einfache mucüse oler mucopurulente Urethritis, welche nicht contagiös ist und zweitens eine blenno:rhagische Urethritis, die direct übertragbar ist and der ein Contagium vivum, der Gonococcus Neisser zu Grunde liegt. Uebrigens macht seine akademische Vorlesung über die Infectivität der Blennorrhagie keinen Anspruch auf Originalität.

Dornig.

Bories (5) berichtet, dass er im Verlaufe einer .,généralisation blennorrhagique" auch ein nach seiner Auftassung zweifellos auf die Gonorrhije zurück zu fübrendes Gluttisüdem beobachtet habe. Im Laufe einiger 'Tage seien bei einer Frau anfgetreten: Endometritis blennorrhoica mit peritonealer Reizung, multiple Gelenkaffectionen, Glottisödem. In der Discussion bringt Bories für seine positive Behauptung nur die Abwesenheit anderer Ursachen für das Glottisödem (wie Erkältung und Albuminurie) und die Coincidenz der verschiedenen Symptome vor. Jadassohn.

Bockhart (6) fand im Eiter eines suppurativen Tripperbubo und eines Periurethralabseesses nur Staplylococcen und zwar Staphylococcus pyogenes aureus, keine Gonococen. Auch im 'Trippereiter fand Bockhart in fünf Fällen von fünfundvierzig Eitercoccen neben den Gonococcen, ausser den Eitercoccen aber stets noch andere Bacterien, so dass die Gelegenheit zu Mischinfectionen hinreichend oft rorhanden ist. Wenn trotzdem die Mischinfectionen nicht so häufig vorkommen, so liegt das daran, dass die im Gewebe der Harnröhrenschleimhaut liegenden weissen Blutzellen einen Wall gegen das Eindringen ebenso der Gonococcen wie der anderen Bacterien bilden. 
Bumm (7) weist auf die Häufigkeit der Mischinfectionen bei Gonorrhöe hin, d. h. Erkrankungen, welche nicht durch die Gonococcen, sondern durch andere Bacterien hervorgerufen sind, deren Eindringen durch die vorher stattgefundene Gonococceninvasion ermöglicht oder doch begünstigt ist. Hierher gehören die Bartholinitis, die Entzündung der Sehleimfollikel der weiblichen Harnröhre, die Cystitis. Bei der Para- und Perimetritis handelt es sich in selteneren Fällen ebenfalls um Mischinfection mit pyogenen Coccen; es gelang Bumm in zwei Fällen von eitriger Parametritis solche im Eiter nachzuweisen. In der Mehrzahl der Fälle gelangt aber das Exsudat nicht zur Schmelzung, hier können daher pyogene Coceen nicht im Spiele sein. In zwei Fällen constatirte er die Abwesenheit von Bacterien im Exsudat, müglicherweise wurden diese gutartigen Fälle von Tripperparametritis überhaupt nur durch das Eindringen chemisch reizender Produkte hervorgerufen, doch sind hierüber noch weitere Untersuchungen anzustellen. In den von der Vulva und Vagina entfernteren Theilen des weiblichen Genital-Tractus werden die anderen Bacterienarten immer spärlicher, in den Tuben finden sich andere Bacterien ausser den Gonococcen bei Trippersalpingitis kaum jemals. Nur eine gonorrhoische Mischinfection, nämlich die mit Tuberkelbacillen, kann hier vielleicht in Frage kommen, ähnlich wie die Genitaltuberculose des Mamnes im Anschluss an Gonorrhöe, besonders gonorrhoische Epididymitis, vorzukommen scheint, lassen sich vielleicht auch Fülle isolirter Tubentuberculose durch eine solche Mischinfection erklären. Auch beim Tripperrheumatismus handelt es sich wohl zweifellos um eine Mischinfection mit pyogenen Mikroorganismen.

Noeggerath (8) erörtert die Schwierigkeiten der Diagnose weiblicher Genitalerkrankungen als gonorrhoischer. Besonders auf den Gonococcenbefund legt er keinen allzugrossen Werth, da derselbe beim Weibe sehr viel schwieriger zu erbringen sei, als beim Manne und überdies auch bei letzterem in mehr als vierzig Percent der Fälle von chronischer Gonorrhöe sich keine Gonococcen finden. Seinen früheren pessimistischen Standpunkt bezüglich der Unheilbarkeit einer jeden Gonorrhöe hat Noeggerath längst verlassen. Die wichtigsten Merkmale der chronischen Gonorrhöe bein Weibe sind die folgenden: 1. Erkrankung einer gesunden. Frau kurz nach der Heirat an einem Leiden der Geschlechtsorgane, welches hä口fig das Wohlbefinden der Betroffenen in einem Grade alterirt, welcher nicht mit den scheinbar geringen Veränderungen in den Sexualorganen übereinstimmt. 2. Eitriger Austluss bei Abwesenheit tiefer Ulcerationen, Granulation, Sarkom oder Carcinom oder glasiges, spärliches Secret mit schmaler, hochrother Erosion am Muttermunde. 3. Katarrh der Ausführungsgänge der Vulvo-Vaginaldrüsen. 4. Kleine spitze Condylome in verschiedenen Localitäten des Scheideneinganges. 5. Ein Kranz von kleinen spitzen Condylomen im Rectum dicht oberhalb des Orificium ani. 6. Die Gegenwart einer Kolpitis granulans 7. Nachweis einer Salpingo-Perimetritis oder 8. einer Ovariitis glandulal is.

Lesser.

Levy (9) bespricht zunächst die Symptome der Gonorrhöe und deren Complicationen bei der Frau, sowie die Therapie, speciell die intra-uterine Behandlung mit Injectionen von' Sublimatlösungen $(1: 4000)$, und mit Auskratzung mittelst scharfen Löffels und nachfolgender Aetzung mit Jodtinctur, Liquor ferri sesquichlor. oder Arg. nitr. Er kommt zu folgenden Schlüssen: 1. Der Gonococcus Neisser ist das specifische, ansteckende Agens. 2. Man findet die Gonococcen sowohl bei den acuten, wie bei den chronischen Formen. 3. Das Auftreten der Gonococcen in den Secreten ist ein wechselndes. 4. Die Intensität der Gonorrhöe steht nicht immer im Ver- 
hältniss zu der Zahl der Gonococcen. 5. Das normale Aussehen der Urethra beweist nicht, dass die Gonorrhöe geheilt ist.

Jacobi.

Prettyman (10) berichtet über echte gonorrhoische Crethritis bei zwei Brüdern von neun und elf Jahren, welche dieselben sich durch Cohabitationsversuche mit einer siebzehnjührigen Negerin zugezigen hatten. Zwei Monate später kam demselben Arzt ein Fall von gonorrnoischer Vulvitis und Urethritis bei einem neunjäligen Mädchen der best $€ \mathrm{n}$ (iesellschaft zu Gesicht. In allen drei Fällen bätten die Hausärzte das Ieiden verkannt und als Balanitis und Eczem der Vulva behandelt, weil sie Gonorrhöe bei so jungen Kindern nicht vermutheten.

Arning.

Mit gutem Erfolg will Abaly (11) eine Mischung von cinem Theil Borsäure zu drei Theilen Glycerin bei Gonorrhöe vorwenden. Fr führt einen Gummikatheter bis zur Pars prostatica, armirt jhn aussen mit einer Pravaz'schen Spritze und füllt beim Zurückziehen die Harnröhre mit obiger Lösung an.

Löwenhardt.

Blanc (12) verlangt für die Behandlung der acuten Gonorrhöe allgemeine Ruhe des Körpers, Immobilisirung der Genitalien (suspensorium). Bettlage hält er nicht für nöthig. Er verbietet Alcoholica; Thee und Kaffee erlaubt er nur mit Einschränkung; in dem massenhaften Wassertrinken sieht er eher Schaden als Nutzen. Anf das Würmste empfiehlt er lauwarme Vollbäder. Gegen Erectionen lässt er kalte Umschlige, Irrigationen machen; er verbietet Riückenlage und zu weiche Lagerung des Patienten. Unter den innerlichen antigonorrhoischen Mitteln hebt er das Antipsrin hervor. Er ist ein Anhänger der Balsamica im initialen Stadium; er gibt sie mit dem Essen. Eine Abortivbehandlung (Arg. nitr. $1^{\circ} 0-10^{\circ} 0 / 1000^{\circ} 0$ ) reservirt er nur für wohlerfahrene Kranke, die ein gewisses Verständniss für die Krankheit besitzen. Das subacute Stadium steht unter dem therapentischen Regime der Adstringentien. Die gesammte Tripperbehandlnng beschliesst $\mathrm{Bl}$ anc nicht ungern mit Bismuthum subnitr. $10^{\circ} 0 / 12 \% 0^{\circ}$. Im Ganzen leitet er die Injectionsbehandlung möglichst früh ein. In technischer Brziehung verlangt er grösste Peinlichkeit. Viele der protralirten, sogenannten unheilbaren Fälle führt er auf Nachlässigkeit in der Unterweisung. auf mangelhafte Ausführung der Injectionen zurück. Besteht am Ende nur noch Ausfluss, so sucht er eine Palpation der Urethra diagnostisch und therapeutisch zu verwerthen, dann hält er sorgsame, vorsichtige Bougirung und Katheterismus der Harnröhre für indicirt.

Friedheim.

Ledetsch (13) empfiehlt namentlich für Gonorrhoea chronica Injectionen von Chininum bisulphuricum $1 \cdot 0$, Glycerin $9 \% 0$, Ail. dest. $75 \cdot 0$. Er injicirt zuerst dreimal, dann zweimal, schliesslich nur einmal tïglich. Er rühmt die Erfolge seiner 'Therapie.

Friedheim.

Currier (14) erklärt sich entschieden gegen die abortiven starken Injectionen bei Gonorrhüe. Er sah von schwachen Füllensteinlüsungen vortrefflichste Erfolge. Currier ist überzeugt, dass Argontum nitricnm die Gonococcen sicher tödtet. Wismuthpräparate wendet Currier gern zur Tamponade bei Blennorrhüe der Vagina an; gleichzeitig aber ist sich $\mathrm{Cur}$ rier wohl bewusst, dass hierdurch die Gonococcen nicht getijdtet werden, vielmehr, dass nur ein für die weitere Entwicklung günstiger Nährboden diesen letzteren geraubt wirl. Der Autsatz ist gegen 0 s borne gerichtet.

Friedheim.

Osborne bezweifelt die Behauptung Currier's, dass Wismuth-Injectionen die Gonococcen nicht tödten, sondern ihnen nur den Nährboden rauben. Dahingegen erinnert $\mathcal{A}$. Rose (15) an eine hieberbezügliehe Beobach- 
tung $\mathbb{K}$ üchenmeister's, der im Initialstadium der Gonorrhüe Injectionen von Kalkwasser 1:4 empfahl. Kalkwasser wirkt wie bei der Diphtherie so auch hier auflockernd auf die Schleimbaut; die entzündete Membran wird bis zu einem gewissen Grade abgelist, den Coccen somit ihr eigentlicher Grund entrissen. Diese Kalkwasserinjectionen, welche stündlich zu machen sind und schmerzlindernd den Entzündungserscheinungen entgegenwirken, führen schon nach ein bis zwei Tagen die Kranken in das subacute Stadium hinüber. Letzteres lässt die Anwendung von Adstringentien zu. Ganz ähnlich wirken nur auf den Schleimhautgrund, also nur indirect auf die Mikroorganismen selbst, Natrium bicarbonicum, Zinkoxyd. Wismuth und Jodoform ein. Nach König sterilisirt Jodoform die Wunde awar, nimmt den Mikroorganismen die Bedingungen, unter denen sie sich zum Schaden des Körpers weiter entfalten könnten - es tültet sie aber nillat. Aus seinen eigenen Erfahrungen empfichlt nun Rose für die Abortiv-Fehandlung der Gonorrhöe auf das wïrmste den Thallin-Antrophor, d. b. den Antrophor von P. Francke - eine Röhre, die aus spriralig aufgewundenem, vernickeltem Draht besteht. Das eine Ende dieser biegsamen Rühre ist halbkugelig, das andere trägt als Handhabe einen Ring. Ein Finniss ron Schellack schützt sie gegen die Einwirkung der Medicamente. Han taucht die Röhre in eine Mischung von Gelatine und Glycerin, man desinficirt sie durch eine zweipercentige Carbollösung. Hat man sie mit dem Medicament imprägnirt, so erbitzt man sie bis zu $86^{\prime \prime} \mathrm{F}$. und lässt sie dann erkalten. J)as ïberaus geschmeidige Instrument passirt die Engen der Urethra. Rose wendet als Medicament eine fünfpercentige Shallinmasse an. Rose betont, dass diese Application in Gegensatze zur analogen gleich starken, selbst schwächeren Injection den Vorzug der Schmerzlosigkeit habe, längere Zeit, bis zu 30 Minuten, vertragen werde und sich ganz vortrefflich für das acute Stadium der Gonorrhöe eigne.

Friedheim.

Osborne (16) bringt eine kurze und übersichtliche Zusanmenstellung der Aeusserungen zahlreicher Syphilidologen, Chirurgen, Grnäkologen und Pathologen aller Länder über Ursache, Beschaffenheit und Behandlung der Gonorrhüe. Danach allein, ohne eigene Erfahrungen ins Feld zu führen, kennzeichnet er den heutigen Stand dieser Frage, durch folgende Thesen: 1. Die Gonorrhöe ist eine specifische Entzündung. 2. Sie wird aller Wahrscheinlichkeit nach durch einen specifischen Mikroorganismus verursacht. 3. Der Gonococcus Neisser's ist fast ohne Zweifel der specifische Mikroorganismus der Gonorrhöe. 4. Die Abortivbehandlung der Gonorrhöe mit ätzenden Einspritzungen ist weder gerechtfertigt, noch befriedigt sie. ö. Die einzige Abortivbehandlung sollte in milden, antiseptischen Einspritzungen bestehen, verbunden mit constitutioneller Behandlung.

Block.

Unter den Schädlichkeiten, welche die Gonorrhoea posterior hervorrufen, erwähnt Otramare (17) in erster Linie die Injectionen. Otramare verwirft durchaus die indifferenten, beruhigenden etc. Injectionen. Abgesehen vom abortiven Verfahren lässt Otramare in den acuten Fällen nie: mals einspritzen. Vor jeder einzelnen Injection lisst er die Patienten den Eiter aus der Urcthra herausdrücken und uriniren. Friedheim.

Rand (18) hält an einer spcejfischen (Gonococcus Neisser) und nicht specifischen Form der Gonorrhöe fest. Er betont für die Therapie den allgemeinen Körperzustand, die Reaction des Harns (Hjperaciditït u. s. f.). Er spricht sich gegen dic starken Diuretica ans und lobt auch als Diureticum ausserordentlich die Milch. Im acuten Stalium reicht er kräftigen Leuten täglich salinische Abfîhrmittel. Ist das Uriniren schmerzhaft, so empfiehlt er cine combinirte innerliche Darreichung ron Extractum 
Hyoscyami und Oleum Santali. Als internes Mittel namentlich bei gleichzeitiger Cystitis - empfiehlt Rand vor Allem Oleum Santali. Im acuten Stadium lässt $R$ and nur dann injiciren, wenn die reizende Wirkung der Injectionen durch ihren therapeutischen Erfolg entschieden überwogen wird, und beginnt dann am liebsten mit Blei- und Zinklösungen, denen er Extractum Belladonn. und Opium zusetzt. Rand glaubt, dass Epididymitis unter dem Einflusse der Injectionstherapie seltener auftritt, als während einer durchaus internen Behandlung. Mit der Behandlung der Gonorrhöe hört Rand erst dann auf, wenn keinerlei Veränderung an dem Meatus urethrae (Ausfluss, Verklebung) wahrznnehmen, wenn lüngere Zeit hindurch keine Spur von Schleim und Eiter in Hurn zu constatiren ist. In der Discussion betont Wackernaghen die antiseptischen Principien (Sublimatinjectionen, häufiger Wechsel der Wäsche, Sitzbäder, Carbolsäure innerlich). Chochraw empfiehlt für das acute Stadium Tinct. Conii, von der er zugleich annimmt, dass sie die Chorda verhindert.

Friedheim.

Empfehlung der Salbensonde bei "sexueller Neurasthenie" und chronischer Gonorrhö̀ zur gleichzeitjgen Erreichung der Adstringirung und mechanischen Compression. Sperling (19) bestreicht das Bongie mit einer zähen, ein- bis anderthalbpercentigen Arg. nitr.-Salbe (aus 4.0 Cera alba zu 20.0 Lanolin) und glättet, die rauhe Aussenseite nivellirend, mit Mandelöl; Daner der Application fünf bis fünfzehn Minuten.

Casper (20) vertheidigt seine cannelirten Neusilbersonden gegenüber den Einwänden von Unna und hebt hervor, dass sie leichter und schonender eindringen, als die glatten Salbensonden, dass, da die Salbe schmilat, auch die gesammte Harnröhrenwand tangirt wird, endlich, dass ihre Starrheit, gegenüber den biegsamen Zinnsonden, kein Nachtheil ist, da eine mittlere Krümmung in fast allen Fällen ausreichend ist. Casper wendet sich auch gegen Sperling, weil dieser bei Empfehlung der Salbensonde gar nicht erwähnt, dass die Methode längst von anderer Seite angegeben worden ist.

Sperling (21) führt Casper gegenüber aus, dass die cannelirte Sonde nur die mit den Metallfächen direct in Berührung kommenden Theile der Urethra comprimiren kann. Je dünner also die Metallrippen sind, desto geringer ist die Compression, je stïrker dieselben sind, je weniger Raum also zwischen ihnen für Salbe bleibt, je geringer die Adstringirung. Zur gleichzeitigen Erreichung beider Zwecke also ist die cannelirte Sonde nicht geeignet.

R. Koln

Tommasoli (22) demonstrirte in der Section für Dermatologie und Syphilis des medicinischen Congresses in Pavia eine nach seiner Angabe construirte Urethralspritze, die den Zweck hat, Medicamente in Salbenform in jeder beliebigen, auch der kleinsten Menge in die Harnröhre einzufülnen. Diese Salbenspritze ist dem bekannten Ultzmann'schen Harnröhreninjector nachgebildet und besteht aus einem Metallkatheter Nr. 18 der Charrière'schen Scala, der $16 \mathrm{Ctm}$. lang ist und an seinem urethralen Ende eine ungefähr $3 \mathrm{Mm}$. weite centrale Oeffinung besitzt. In diesem leicht gekrümmten Katheter lüuft ein mit Leder äberzogener Stempel an einer mehrgelenkigen metallnen Stempelstange, die an ilırem äusseren Ende eine Scala trägt, mittelst welcher die zu injicirende Salbenmenge genau bestimmt werden kann - jeder Theilstrich entspricht dem Fünftel eines Cubikcentimeters. Der Katheter ist mit einer bequemen Handhabe aus Hartkautschuk versehen, die durch einen Einschnitt anzeigt, auf welcher Seite sich die Katheterkrümmung befindet. Zur Füllung der Spritze genügt, wenn die Salbe weich ist, die Aspiration des Stempels; wendet inan dagegen eine 
consistentere Salbenmasse an, so geschieht die Füllung dadurch, dass die Salbe mittelst einer gewöhnlichen Glasspritze durch die Katheterüffnung eingetrieben und gleichzeitig der Stempel langsam herausgezogen wird. Tommasoli versuchte seine Salbenspritze während eines längeren Aufenthaltes in Wien in Gemeinschaft mit Docent Dr. Finger in zahlreichen Fällen von chronischer Urethritis und erzielte damit sehr befriedigende Resultate. Als Salbenconstituens verwendet er ausschliesslich Lanolin. Die bis nun angewendeten Salben sind folgende: 1. Nitras argenti $0 \cdot 1-1 \cdot 0$, Lanolin 45\%0, 0l. olivarum 5.0. Alle Vortheile, welche die Salben bei der localen Therapie iiberhaupt bieten, und speciell jene des Lanolins, welches an der Schleimhaut durch längere Zeit fest adhärirt und selbst durch den Harn nicht so leicht fortgespült werden kann, wodurch eben der Contact des Medicamentes mit der erkrankten Schleimhant ein viel innigerer und länger dauernder wird, als bei Anwendung flüssiger Medicamente, lassen sich, wie Tommasoli hervorhebt, durch seine Salbenspritze erzielen. Weitere Vortheile des Instrumentes sind seine fast absolute Reizlosigkeit, sowie die Möglichkeit, die Salbe an jede beliebige Stelle der Urethralschleimhaut zu appliciren.

Dornig.

Petersen (23) empfiehlt an Stelle der Tripperspritze einen Irrigator, welcher aus einem am unteren Ende mit einer ausgezogenen Oeffnung versehenen Probirgläschen besteht. Ueber die Oeffinung wird ein Gummischlauch gestülpt, der am anderen Ende eine der Urethralöffnung des Patienten angepasste Glasolive trägt. (Der Vorschlag ist keineswegs neu. Ref.)

Lesser.

Das von Zuelzer (24) angegebene Instrument besteht aus einer hutartig die Glans penis bedeckenden Glocke, in welcher sich Oeffnungen für $\mathrm{zwei}$ concentrische Röhren befinden, die für die Harnröhre bestimmt sind. Die äussere derselben besitzt schlitzförmige Oeffnungen, um den Flüssigkeitsstrom herauszulassen, und dient gleichzeitig als Abflussrohr. Aussen an der Glocke befindet sich je ein mit den beschriebenen Röhren communicirendes Zu- und Abflussrohr. Der Apparat, durch welchen täglich zwei bis drei Liter einer $6 \%$ Kochsalzlösung in die Harnröhre irrigirt werden, dient dazu, die Harnrơhre vor der medicamentösen Behandlnng von dem schleimigen Secrete zu befreien.

Der Apparat Groeningen's (25) besteht nicht wie der von Lohn. stein (Berl. klin. Wochenschr. 21. Nov. 1887, cf. Ref. in dieser Zeitschrift) beschriebene aus zwei concentrischen Röhren, sondern aus einem Katheter, dessen eichelförmiges proximales Ende an zwei gegenüber liegenden Stellen seiner Basis je eine Oeffnung für den rückläufigen Strom besitzt. (Ein besonderer Vorzug vor einem gewöhnlichen Katheter ist nicht einzusehen. Ref.)

Herxheirner.

Schütz (26) hat zu medicinischen Beleuchtungszwecken, ganz besonders für die Endoskopie, einen neuen Beleuchtungsapparat angegeben, bei welchem das Glühlicht - "schwimmgürtelartig" - in der Mitte durchbolırt ist. Dieses Glühlicht ist an einem Reflector mit Handgriff, respective einer Stirnbinde befestigt und das beobachtende Auge sieht durch die centrale Oeffnung hindurch. Die Erwärmung wird durch Anbringung von Luftzugcanälen verhütet.

Lesser.

Allen (27) berichtet über die Resultate, welche er bei der endoskopischen Untersuchung von fünf Fällen chronischer Gonorrböe (zum Theil mit beginnender Strictur) mit einem von Klotz angegebenen Endoskop aus Silber erhalten hat; als Lichtquelle wurde eiu Argand-Brenner benutzt, dessen Licht mittelst eines am Kopfe angebrachten Spiegels reflectirt wurde; 
am vorderen Ende des Endoskops war eine Guttaperchaplatte angebracht, um die Reflection des Lichtes za verhindern and zugleich das Präputium zurückzuhalten. Der Verfasser berichtet über mehr oder minder huchgradige Congestion der Urethralschleimhaut, Gefässinjection, Starrheit der Urethralwände, die er mit dem Endoskope constatiıt und unter Hilfe des Endoskops mit ein- bis dreipercentigen Arg. nitr.-Lösungen behandelt habe; die Fialle, welche Verfasser beschreibt, bieten nichts Besonderes dar; auch die Heilerfolge sind, wie sich Allen nicht verhehlt, keine besonders grossartigen. $\mathrm{Ob}$ sich dasselbe Resultat in den beschriebenen Fälen nieht auch mit anderen Untersuchungs- und Behandlungsmethoden hätte erreichen lassen, bleibt unerörtert.

Jadas s o hn.

Friedrich (28) empfiehlt eindringlich den Gebrauch des Endoskops in allen hartnäckigen Fällen von Urethritis behufs Diagnose und Theripie (lucaler Aetzung). Er bevorzugt einfache Röhren aus Metall oder Hartgummi. Er verkennt niclit die Schwierigkeit der endoskopischen Diagnose, doch Uebung gebe schliesslich auch darin Sicherheit. Zur Illustration erwähnt er zwei Fälle aus seiner Praxis. Beide litten an eitrigem Ausfluss und Schmerzen beim Utiniren, keine periurethrale Schwellang, kein schmerzhafter Punkt, kein Blut in Secret. Sie warden erfolglos antigonorrhoisch behandelt. Das Endoskop zeigte bei dem einen ein Geschwür auf der oberen Harnröhrenwand, einen Znll hinter der Mündung; später sicherten Lymphadenitis und specifisches Exanthem die endoskopische Diagnose: syphilitischer Primäraffect. Bei dem anderen machten erst die constitutionellen Symptome auf den Irrthum aufmerksam; das Endoskop zeigte die Narbe des urethralen Primäraftectes.

Block.

Belfield (29) bougirte einen Patienten mit Strictura urethrae. Er gab dem Kranken zuror eine Injection von vierpercentigem Cocaĩn in die Uretlira und führte die Sonde dann mühelos eiv. An siebenten Tage nach diesem Eingriff wurde der Patient sehr reizbar und schlief mehrere Näclite vicht. Am neunten Tage sollte das Verfahren in gleicher Weise wiederholt werden. Unmittelbar nach der Injection klagte der Kranke über Schwindel und fiel plötzlich todt in den Stuhl zurück. Die Autopsie ergab zwei blutstrotzende Nieren. Belfield nimmt an. dass der Kranke urämiscl war, und die einfache mechanische Reizung der Urethra die Todesursache abgab.

Friedheim.

Lava ux (30) kommt in seiner Arbeit über die Antisepsis der Blase und der Urethra ${ }^{*}$ zu folgenden Schlüssen: 1. Die permanente Ausspülung des vorderen Theiles der Urethra und die intra-vesicalen Injectionen olne Sonde bieten ein einfaches-und unschädliches Mittel, die Urethri und die Blase vollständig zu desinficiren. 2. Dieses Mittel ist bei den meisten Stricturen der Urethra anwendbar. 3. Dank dieser vollstïndigen Antisepsis und der antiphlogistischen Wirkung der heissen Injectionen in die Blase, sind die der "rapiden Dilatation" zugeschriebenen Complicationen jetzt sehr selten. 4. Bei der Buhandlung der einfachen und leicht zu dilatirenden Stricturen soll die "rapide Dilatation" überhaupt an die Stelle der allmäligen Dilatation treten, die selten zu Recht besteht. 5. Die ohne Sunde gemachten intra-vesicalen Injectionen genügen, nm die Weite der dilatirten Urethra zu erhalten. 6. Die Indicationen zur Urethrotomia interna werden bis aufs Aeusserste hinansgeschoben. 7. Die permanente Bespülung des vorderen Theiles der Urethri und die Blaseninjectionen ohne Sonde inüssen. da sie gestatten diese Theile vollständig zu desinficiren die gewaltsame Dilatation und die Urethrotomia interna zu einem weit leichteren Eingriff inachen. 
Hartmaun (31) scheidet aus den ätiologisch verschiedenen Cystitiden die besonders schmerzhaften und vor Allem schwer zu belsindelnde Fälle

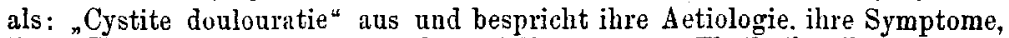
ihren Verlauf, die Diagnose und speciell im zweiten Theile ihre Behandlung: die medicamentöse, die "chirurgische ohne Operation" (Cocaïn), Borsäure etc., bezw. Arg. nitr.-Lüsungen - alle Auswaschungen aber sollen nur mit geringen Quantitäten von Flüssigkeiten vorgenommen werden; ein weicher Verweilkatheter stellt die Blase ganz ruhig und gibt oft schnelle Erfolge, und endlich die operative Behandlung. Die Dilatation des Blasenhalses bei der Frau ist erfolglos bei der tuberculösen Cystitis und bei schweren Fällen, sie heilt nur die mittelschweren. Das letzte Mittel ist die Anlegung einer Blasen-Scheidenfistel (Bozeman, Emmet), für welche der Verfasser eine etwas modificirte Methode mittelst eines eigens construirten cannelirten Katheters angibt; durch diese Fistel wird dann die medicamentöse Behandlung der Blase vorgenommen; erst wenn diese vollständig abgeschlossen, darf man die Fistel sich schliessen lasseu. Jadassohn.

Denny (32) veröffentlicht die Heilung einer Urethralstrjctur dureh Sprengung. Der dreissig Jahre alte Patient hatte acht Jahre vorher eine Gonorrhöe acquirirt, zu welcher sich eine Strictur hinzugesellte. In Folge ungeschickter Versuche, diese zu erweitern, entstanden zwei Urinfisteln, welche durch Operation geschlossen werden mussten. Seitdem war der Urinstrahl immer dïnner geworden. Ausser einer leicht durchgängigen Strictur. 2 Zoll vom Orificium entfernt, fand sich eine zweite in der Entfernung von $5 \%$ Zoll, welche zunächst nicht einmal die dünnste Sonde durchliess. Nach verschiedenen Sitzungen und nachdem er die Urethra bis zur Strictur mit dünnen Sonden angefüllt hatte, gelang es Denny zuerst eine ganz dünne Fischbeinsonde und über diese hinweg Gouley's Hoblsonde Nr. 1 und 2 (englisch), später auch einen sehr dünnen Gummikatheter ( $\mathrm{Nr}$. 1) durchzuführen, durch welch letzteren der Urin langsam abträufelte. Die Strictur in 2 Zoll Entfernung vom Orificium konnte bald mit. Nr. 17 (französisch) überwunden werden, während die in ${ }^{3} 1 / 2$ Zoll Entfernung stets nur Nr. 2 (engliscb) durchliess. Verfasser schritt nun zur Sprengung der Strictur. Der Urin wurde normal befunden. Nach Injection einer vierpercentigen Cocaïnlösung führte Denny über die Fischbeinsonde hinweg den ron Gouley modificirten Thompson'schen Dilatator durch die Strictur bindurch, zog die Fischbeinsonde zurück und öffnete den Dilatator plötzlich so weit als möglich. Dann zog er ihn zurück, führte ihn wieder ein und dilatirte die Strictur auch in querer Richtung. Es erfolgte keine bedeutendere Blutung. Der Patient musste nach der Operation das Bett hüten und erhielt ein Suppositorium aus Chin. sulph. und Morph. sulph. An nächsten Morgen kein Fieber, keine Schmerzen; Urin blutig. Der Patient blieb fünf Tage zu Bett; er befand sich ganz wohl; der Urin wurde mit Leichtigkeit im dicken Strahle entleert. In der ersten Zeit nach der Operation wurde mit $\mathrm{Nr} .17$ (französisch) bougirt. Zwei Wochen nach der Operation zeigte sich eine geringe Neigung der Strictur, sich wieder zu verengern. Den ny liess jetzt den Patienten alle vierzehn Tage $\mathrm{Nr}$. 12 (englisch) einführen, was den Erfolg hatte, dass die Strictur dreiviertel Jahre später noch ebenso durchgängig war, wie kurz nach der Operation. Denny schliesst aus diesem Fall, dass für tiefsitzende Stricturen in der Nähe und in der Pars membranacea die Sprengung ebenso ausreichend, ansserdem viel sicherer ist, als die Urethrotomia interna, weil bei der ersteren Operation die Gefahr einer bedeutenderen Blutung äusserst gering ist. Die Urethrotomia externa sollte nur ganz ausnahmsweise angewandt werden. Bei Vornabme der Sprengung sind nach Denny folgende Punkte besonders zu beobachten: 
1. Die Entfernung der Strictur vom Orificium muss gronu testgestellt werden. 2. Der Punkt der grössten Ausdehnungstähigkeit mass genan in die Strictur zu liegen kommen. 3. Die Dilatation miss schnell. nicht allmälig geschehen. Ausserdem empfiehlt es sich, dic Lrethra nach zwei Richtungen hin zu dehnen. 4. Vor dem Zurückziehen des Diliatators inulss derselbe zuerst nach der Blase zu vorgeschoben werden, intem nan d:chei zuzuschrauben beginnt. Dann ziehe man das Instrument herans. wobei man dureh langsames Zuschrauben dis Branchen des Instrumentes einanler nähert, dadurch vermeidet man, dass sich die Schleimhaut zwischen den Blättern des Dilatators verfängt und beim Herausziehen desselisen gezcrit wird. 5. Ein Suppositorium aus Chinin und Morphium ist ein ansgezeichnetes Prophylacticum gegen Urethralfieber. - Nach allen Operationen wh lange bestehenden traumatischen Stricturen muss eine Sonile erst allo vierzehn Tage, später alle Monate cinmal einige Jahre lang eingetiul:rt werden. Dieselbe soll so dick genommen werden, als es das Orificium des Patienten gestattet. Zum Schluss kommt Denny noch auf lie ron D: R. Newman in New-York empfohlene Elektrolyse der Stricturen zu sprechen. Falls sich die Empfehlungen bewahrheiten, würde in Zukunft wohl a?sschliesslich diese Methode angewandt werden. Die Art der Anwendung hat Dr. Newman in dem diesjährigen Journal of the American Melical Association ausführlich beschrieben.

Zeising.

Eine ältere Idee in vielleicht praktischerer Form hat $\mathrm{Mad}$ ack (33) ausgebildet. - Um die vor der Verengerung gelegenen Partien der stricturirten Harnröhre vor unnöthigen Insulten bei schwer zu sonäirenden Stricturen zu schätzen, schiebt er eine hohle silberne, mit leichter Krümmung versehene Leitsonde bis an die Strictur vor und durch diese die feineren Bongies oder Katheter. Die centrale Oeffnung gestattet einem Katheter von $\mathrm{Nr}$. 2 englischer Scala den Durchtritt, einige engere Huhlräume in der Wand des Instrumentes erleichtern das Sondiren engster Stricturen mit Darmsaiten oder feinsten Bougies. Das Instrument kamn bezogen werdeu von Walters \& Co., 29 Moorgate Street, London.

Morton (34) plaidirt für die durch Steavenson und Brace Clarke in England eingeführte elektrolytische Behandlung der Harnröhrenstricturen. Einen seit einem Jahre wegen schwerer Cystitis mit Urinfisteln am Sehaft des Penis, des Scrotums und Perineums vergeblich behandelten Patienten gelang es mit dieser Methode innerhalb vier Wochen vollstäntig zu beilen. Die den negativen $\mathrm{Pol}$ repräsentirende Bungieelektrode (Nr. 7 englischic Scala) wurde mit einer Stromstärke von 8-9 Milliampère (höhere Ströme nicht empfehlenswerth) bis an die Strictur gebracht und gleitet nach $;$ i bis 6 Minuten schmerzlos hindureb. Die Anode wird dabei indifierent aufgesetzt. In ferneren Verlauf der Behandlung gelang es in sechs weiteren Sitzungen darch Application der Kathode in den tieferen Partien der Urethra und der Anode an den äusseren Fistelötfnungen, sämmtliche bereits stark callösen Fistelgänge zu erweichen und ohme andere Medication cumplet auszuheilen.

Arning.

Einen Beweis für die Brauchbarkeit der elektrolytischen Behandlung der Urethralstricturen liefert $\mathrm{New}$ an (3̈) nit einer sehr sorgtältigen uni kritischen Zusammenstellung des zweiten Hundert derartig gebesserter uni geheilter Fälle, dass er die Elektrolyse für eine völlig un refährliche und gerale in den Fällen, wo andere innere Dilatationsverfahren nicht meth: möglich sind, vorzügliche Metlıode erklären kinn. Erst die jahrelang: Beobachtungsdauer des in jeder Richtung sorossum genchichteten Materials entscheidet die Definition Heilung. Die genauere Besprecinung einzeluer, 
recht interessanter Fälle muss im Originale nachgelesen werden, die Hauptregeln der Behandlung lassen sich in Folgendem zusammenfassen: 1. Es sollen möglichst schwache Ströme angewendet werden, damit eine langsame "chemische Absorption" der Strictur erzielt wird ("keine Cauterisation?"). 2. In Contact mit der Strictur kommt das eiförmige Metallende der im Uebrigen isolirten Bougies (mit kurzer Krümmung). 3. Bei der Operation wird die grösste Vorsicht angewendet um event. Shok zu vermeiden. Man steigt Jangsam von Element zu Element, um die Empfindlichkeit des Patienten auf elektrische Ströme zu prüfen, wiederholt Sitzungen erst nach einigen Tagen, wendet niemals zwei Elektroden-Bougies binter einander an. Die Bougies müssen die Stricturen ohne die geringste gewaltsame Beihilfe passiren. 4. Anaesthetica sind contraindicirt, da der Patient gerade fühlen soll. Bei Entzündungsvorgängen wird die Elektrolyse ansgesetzt. 5. Der Strom wird erst geöffnet, wenn die Bougies bereits eingeführt sind und geschlossen, ehe sie entfernt werden. 6. Jede Strictur kann auf diesem Wege passirt werden.

Lö wenhardt.

Desnos (36) berichtet. über folgenden anamnestisch und klinisch interessanten Fall: Ein Mann von zweiundfünfzig Jahren hat vor zweiunddreissig Jahren eine ohne Einspritzungen behandelte, sehr lange währende Gonorrhöe gehabt; seitdem völlige Gesundheit. 188ว zwei Monate lang Entleerung von Eiter aus dem Rectum ohne sonstige Beschwerden, einige Monate darauf Bildung eines Abscesses, der nach der Incision mit Hinterlassung einer Fistel heilte. Im December 1886 begannen Defäcationsbeschwerden; im Jänner 1887 Bildung eines neuen Abscesses links am Perineum, dicht am Scrotun; die frühere Fistel bestand noch immer; sie war ebenfalls nach der linken Seite des Perineums gerichtet - vom Rectum durch eine dichte Gewebsschichte getrennt. Die geschilderten Erscheinungen konnten weder vom Rectum noch von dem Knochen ausgehen; dagegen bestand eine Urethralstrictur in der Gegend des Bulbus urethrae und gleich hinter der Analöffnung konnte eine klappenartige, das Rectum verengernde Vorwollbung im Niveau der Basis der Prostata constatirt werden - oberhalb derselben fand sich nur eine fibröse Induration - vom Drūsengewebe der Prostata keine Spur. Es muss sich also um einen der bei Stricturen gar nicht seltenen Prostataabscesse gehandelt haben, der sich nach aussen entleert und zu einer Zerstörung der Prostata geführt hatte. Der Abscess wurde gespalten, eine kleine Fistelöffnung blieb zurück. Im September 1887 kam der Patient wieder ins Hospital. Er hatte jetzt eine am Rectum hinauf führende Fistel und die Rectalstrictur hatte sebr zugenommen: von der Prostata war nichts zu fühlen. Der Verfasser macht auf die Seltenheit des Falles aufmerksam. Die Prostataeiterung war nach seiner Anschauung die Ursache der Rectalstrictur gewesen; nur noch ein ähnlicher Fall ist ihm bekannt; Tuberculose glaubt er ausschliessen zu können. Die Erfolge der Behandlung - Spaltung der ganzen Fistel - werden noch nicht mitgetheilt. Jadass ohn.

Eine kurze und klare Uebersicht gibt Wils on (37), indem er sich an die Untersuchungen von Cruveilhier, Mercier etc. und besonders an Thompson hält. Eine eingehende Berücksichtigung findet in der Betrachtung der pathologischen Zustände nur der sogenannte "mittlere Lappen“, besser mittlere Partie genannt, da er keinen isolirten Theil darstellt, dessen senile Vergrösserung mit gewissen Involutionsvorgängen des Uterus verglichen wird und keinerlei entzündliche Vorgänge darbietet. Finen operativen Eingriff hält Verfasser nach Erschöpfung sämmtlicher Palliativ-Massnahmen für angezeigt and spricht sich im Allgemeinen auch gegen die partielle Excision des Lappens aus, wie sie jetzt von Landerer (Deutsche

Vierteljahresschrift f. Dērmatol. u. Syph. 1888. 
Zeitschr. f. Chir.) mit Hilfe des medianen Perinealschnittes ausgefübrt wurde und früher schon von Mercier geübt ist. Drei Patienten des Letzteren hatte Guy on Gelegenheit nach lïngerer Zeit zu untersuchen und war mit den Resultaten niclit zufrieden. Erwähnt wird noch die elektrische operative Behandlungsmethode Bottim's, der guten Erfolg batte.

Um dem Mangel eines vergleichenden Massstabes für die Beurthejlung der Prostatagrösse und -Veränderungen abzuhelfen, fertigt Fenwick (38) Thonmodelle an. Während der Zeigefinger der rechten Hand Stück für Stück genau die hintere Blasenwand und Prostata abtastet, fährt der linke Index in gleicher Weise über den vorher verfertigten provisorischen Thonabdruck. Durch die gleichmässige Bewegung der beiden tastenden Finger sollen überraschend genaue Abdrücke liergestellt werden können.

New man (39) war beständig bemüht, die von ihm erfundene und in Juni 1886 in St. Louis der amerikanischen medicinischen Gesellschatt vorgeführte galvanokaustische Sonde zu verbessern, um für Blasen- und Urethraloperationen ein brauchbares Instrument $\mathrm{zu}$ erhalten. Die genaue $\mathrm{Be}$ schreibung muss im Original nachgelesen werden. Das kurz gekrüınmte katheterförmige, handliche Instrument ist gefenstert; in diesem Fenster befindet sich eine galvanokaustische Schlinge. Die wesentlichen Vorzïge bestehen in der constanten Controle des Stromunterbrechers durch den Zeigefinger, dem exacten Arbeiten der Platinschlinge, welche nicht durch Gewebstrümmer isolirt werden kann, da die Katheterhöhlung getüllt, und der leichten Handhabung ohne Assistenten. Wie Referent schon Gelegenheit hatte, bei Besprechung der vorzäglichen Resultate der elektrolytischen Behandlung der Stricturen auseinander zu setzen, verlangt Newmann eine besondere Fürsorge für die elektrischen Apparate; anch für die Galvanokaustik ist eine gewisse Controle nöthig, so dass im Augenblick des Stromschlusses eine Rothglühhitze eintritt, welche kurz vor der Weissglühhitze ist. Für die galvanokaustische Prostatotomie zieht Verfasser den huhen Steinschnitt deshalb vor, weil eine Verletzung der Ureteren nicht vorkäme, einer Perinealfistel vorgebeugt würde, die Nachbehandlung und der Blasenkatarrh besser behandelt werden könne, besonders aber der Operateur sieht, was er thut, und nicht im Dunkeln arbeitet. Es ist hier nicht der Ort, die schon oft discutirte Frage, ob Perinealschnitt oder Sectio alta vortheilhafter, zu beleuchten. Jedenfalls gewährte auch dem Dr. Lange (Ann. of. Surgery, Vol. V, pag. 558) die Sectio alta mit nachfolgender galvanokaustischer Prostatotomie bei einem sechzigjährigen Manne ein vorzügliches Resultat. Der Fall war noch durch die Anwesenheit von zwei Steinen complicirt.

Löwenla ard t.

Thompson (40) berichtet in der Sitzung der Clinical Society of London rom 11. November'1857, über einen Fall von enormer Prostatahypertrophie mit multiplen freien und abgeflachten Blasensteinen. Jahrelanger Katheterismus war voraufgegangen, der vierundsechzigjälrige Patient sehr heruntergekommen. Der freie Stein wurde in einer Sitzung lithrotripsirt, die abgesackten durch den medianen Perinealblasenschnitt entfernt. Da die Reizerscheinungen fortdauerten, machte Verfasser ein halbes Jahr darauf den hohen Blasenschnitt, reinigte die Blasenschleimhant gründlich von fest adhärirendem, fibrinüsem, mit Phosphaten durchsetztem Belag, und entliess den Patienten, der sich rasch erholte, mit einer silbernen Bauchplatte, welche ein in die Blase reichendes weiches Katheterstück und daran befestigt ein Receptaculum urinae trug. Patient befindet sich jetzt nach anderthalb Jahren kräftig und wohl; der Urin ist klar und normal. Th ompson empfiehlt das neue Verfahren sehr warm für derartige schwere Fälle. In derselben Sitzung berichtet dann Gill über drei Fälle von hohem 
Blasenschnitt und Resection der bypertrophirten Prostata vom. Inneren der Blase aus. Alle drei Fülle verliefen mit ausgezeichnetem Erfolge; der Urin wurde gewöhnlich schon am Tage nach der Operation klar; die Bauchwunde heilte ohue Fistel und der Urin konnte in allen Fällen trotz vorherigen jahrelangen Gebrauches des Katheters gut retinirt und spontan entleert werden. Auch Barwell berichtete über günstige Resultate dieser Operation in einer Reibe von Füllen. Thompson drückte seine grosse Freude über die Erfolge aus, doch meinte er, dass man nicht in allen Fällen, wo jahrelanger Katheterismus voraufgegangen, auf die Herstellung der musculären Function der Blase rechnen dürfe und dann, dass seine Methode der permanenten Drainage der Blase durch den hohen Schnitt die Vortheilhafteste sei. In der Discussion äusserte sich die allgemeine Stimmung für das Verlassen der Operation der Prostatahyperfrophie vom Damme aus und für das Freilegen des Operationsfeldes von der Blase aus. A rning.

Thacher (41) stellte einen - zum Theil in der Prostata gelegenen Urethralabscess vor; es fanden sich ferner folgende Veränderungen: Chronische Cystitis, Hypertrophie der Blase, Dilatation des einen, Verdickung des anderen Ureter, eitrige Nephritis und Pyelitis - zum Theile diphtheritischer Natur - in der einen Niere. Klinisch war nur Schmerz in der Nierenund Blasengegend und Incontinenz beobachtet worden. Keine Strictur. Näheres über die detiologie ist in dem kurzen Referat nicht angegeben.

$$
\text { Jadissohn. }
$$

Montaz (4.2) macht auf eine neue acute Form von Tuberculose des Hodens und Nebenhodens aufmerksam, die sich im Anschlusse an acute oder chronische Blennorrhöe entwickelt. Sie gleicht anfangs der blennorrhoischen Affection, doch bleibt trotz aller Behandlung auch wach Wochen noch der Hoden geschwollen, wenn auch schmerzlos. Schliesslich bilden sich Erweichungsherde und Abscesse; das Bild der tuberculosen Orchitis ist fertig. Verfasser meint, dass Tripperkranke tuberculöser Hodenerkrankung stets ausgesetzt sind, besonders wenn es sich um hereditär oder anderweitig tuberculös belastete Individuen handelt.

Block.

Kadler (43). Es werden Pinselungen der Feigwarzen nit Sublimatcollodium als etwas Neues empfohlen.

Falcone (44). Ein Schiffskoch erkrankte nach einem unvorsichtig genommenen kalten Bade an einer rheumatisehen Affection der unteren Extremitäten, verbunden mit sehr heftigen Schnerzen längs der Wirbelsäule. Die Erkrankung liess eine Parese der unteren Extremitäten zurück, die eine neunmonatliche Behandlung nothwendig machte. Zwei Jahre darauf, nachlem der Kranke lüngst wieder hergestellt war, acquirirte er eine Urethritis, zu welcher nach wenigen Tagen nenerdings eine schmerzhafte Schwellung der Gelenke an den unteren Extrenititen trat. Nach der Ansicht Falcone's hat die Blennorrbagie durch Reizung der nervüsen Centren anf reflectorischem Wege die Arthritis hervorgerufen. Für ihn steht es ausser Zweifel, dass im vorliegenden Falle die vorhergegangenen spinalen Störungen, zur Entwickelung der Arthritis blennorrhagica wesentlich beitrugen.

Dornig.

Bei einer eitrigen Kniegelenksentzündung, welche das Recidiv einer vor zwei Jahren zuerst aufgetretenen gonorrhoischen Gonitis darstellte, fand $A$ ubext (45) in dem mittelst Pravaz'scher Spritze entnommenen Eiter keine Gonococcen und schliesst daraus, dass diese bei allen derartigen Gelenksaffectionen fehlen. Jacobi.

Wagner (46) benutzte in zehn Fïllen von Spermatorrhöe den elektrischen Strom mit im Allgemeinen günstigem Erfolg. Den faradischen Strom 
empfiehlt Verfasser besonders bei Onanisten und dergleichen, den galvanischen bei Spermatorrhöe auf gonorrhoischer Busis, und zwar soll man die Anode in der Gegend des Lendenmarks, die Kathode auf dem Damm aufsetzen.

Herxheimer.

Nachdem man als die Ursache der Impotenz eine ausserordentliche Hyperästhesie der tieferen Theile der Urethra entdeckt hat, muss dieselbe entweder durch Sedativa oder Gegenreize beseitigt werden. Zu dem Zwecke kann man entweder Zugpflaster oder Blutegel zu beiden Seiten der Raphe des Perineums appliciren; ferner Morphium, Belladonna, Cocaïn, Eis oder Eiswasserinjectionen ins Rectum, oder wenn das nicht hilft, kann man die drei genannten Medicamente in die Urethra injiciren und alle paar Tage eine stählerne Sonde von starkem Kaliber einführen. Sobald die Reizbarkeit der tieferen Theile der Urethra sich gemildert hat, muss man eine Elektrode in Gestalt eines Bougies in die Urethra einführen, während man die andere auf die Wirbelsäule aufsetzt. Phosphorigsaures Zink, Strychnin oder Canthariden sind nur von Vortheil bei vorhandener Anästhesie der Nerven.

Zeising.

Stewart (48). Die congenitale Phimose, welche meist mit dem Eintreten der Erectionen des Penis verschwindet, ist ein sehr hänfiges Vorkommniss und die Quelle mannigfaltiger Leiden der Kinder. Bei der Untersuchung findet man die Glans gewöhnlich vollständig versteckt, an ihrer ganzen Oberfäche mit der Schleimhaut des Präputiums verwachsen, dazwischen hie und da kleine harte und reizende Substanzen von käsiger Beschaffenheit eingebettet, hinter der Corona eine noch grössere Anhäufung dieser Massen. Dabei ist die Oeffnung des Präputiums zuweilen nur stecknadelkopfgross. In Folge davon uriniren die Kinder häufiger, die Windeln sind beständig nass, der Penis und die umgebenden Theile gereizt und entzündet. Besonders ist letzteres der Fall an der Mündung der Urethra, wodurch beim Urinlassen die heftigsten Schmerzen entstehen, welche die Kinder durch lautes Schreien zu erkennen geben. Die Phimose kann nun die Veranlassung zur Onanie werden und so auf das Allgemeinbefinden nachtheilig einwirken. Aber auch andere, auf dem Wege des Reflexes zu Stande kommende Störungen können mit Phimose in Zusammenhang stehen, z. B. Krämpfe, welche gewöhnlich auf das Zahnen, Verdauungsstörungen und Eingeweidewürmer zurückgeführt werden. Stewart führt einen Fall von Krämpfen mit nachfolgender Lähmung der einen Körperhälfte and der Sprache an, den er durch Circumcision der bestehenden, bedeutenden, starke Entzündungserscheinungen verursachenden Phimose geheilt hat, nachdem innerliche Medication gar keinen Erfolg gehabt hatte. Da nun aber bei den meisten Eltern, besonders bei den Müttern der. Vorschlag einer blutigen Operation fast stets auf Widerspruch stösst. so hat Verfasser eine neue Methode der Bebandlung ersonnen. Bei der Phimose ist die äussere Haut des Präputiums schlaff und frei, die Schleimhaut dagegen hängt häufig mit der ganzen Oberfläche der Glans penis zusammen. Selbst nach der Circumcision kann in diesen Fällen die Vorhaut nicht zurückgezogen werden, wenn man nicht die Schleimhaut abreisst oder zuror spaltet. Um nun das Präpntium durch unblutige Operation zuräckbringen zu können, hat S te wart ejn Instrument erfunden, welches mit seinen vier Blättern die Theile der Schleimhaut gleichmässig dehnt und zu gleicher Zeit die Adhäsionen allmälig löst. Hat man so den vorderen Theil der Glans blossgelegt, so kann man, falls sehr feste Verwachsungen vorbanden sind, dieselben bis zur Corona hin mit dem platten Ende einer Sonde zerreissen. Dabei findet man hie und da stecknadelkopfgrosse harte Granulationen zwischen Glans und Schleimhaut des Präputiums eingelagert, welche als Fremdkörper nach- 
theilig wirken; hinter der Corona in der Regel eine grössere Anhäufung von Smegma. Dann werden die Theile mit einer Salbe eingefettet, die Vorhaut vorgezogen und die Operation ist ohne oder nur mit ganz minimaler Blutung vollendet. Die Anästhesie wird durch zehn Percent Cocaïn bewirkt. Beim Einführen des von Stewart sogenannten "Präputialdilatators" in die Oeffnung des Präputiums muss man sich vorsehen, dass das Instrument nicht in das Orificium urethrae gelangt, weil sonst beim Auseinanderweichen der Blätter eine Zerreissung der Urethra erfolgt. Das Präputium darf nicht plötzlich gedehnt werden, damit weder Schleimhaut noch Haut einreisst und so bei der Heilung durch Narbencontraction wieder eine Verengerang entsteht. Besser ist es, besonders in schwierigen Fällen, von Zeit zu Zeit die Operation zu wiederholen, bis sie vollständig gelungen ist. Das Stewart'sche Instrument besteht in einer über die Flïche gebogenen Scheere, welche vier Blätter hat, die sich beim Schliessen der Scheerengriffe von einander entfernen. Zwischen letzteren befindet sich die Feder, welche den $Z$ weck hat, im Ruhezustande die Griffe auseinander-, die Blätter dagegen zusammenzuhalten.

Zeising.

\section{Venerische Helkosen.}

1. Ingria V. E. Ulcere non infettanti della vagina. - Gazz. degli ospitali $1887,83$.

2. Mannino L. Un nuovo mezzo di cura abortiva dei bubboni. - La riforma med. 1887.

3. Heath. Concerning the treatment of bubo by extirpation of the Glands. - Buffalo, Medical and Surgical Journ. Nr. V, December 1887.

Entgegen den Behauptungen Rollet's, Fournier's, Profeta's und Gamberini's beweist Ingria (1) an der Hand eines reichen klinischen Beobachtungsmateriales, dass das Vorkommen venerischer Helkosen an der Vaginalschleimhaut kein gerade seltenes ist. und unter hundert Fällen ungefähr vierzehn Mal beobachtet wird. Die Helkosen haben ihren Sitz zumeist an der hinteren Wand im unteren Drittel der Vagina; im oberen Drittel findet man sie gewöhnlich am Scheidengewölbe, im mittleren sind sie am seltensten. Wie Ingria hervorhebt, findet seine Beobachtung in den Angaben Andronico's, Rasumow's und Jordan's ihre Bestätigung.

Mannino's (2) Abortiveur der Bubonen besteht darin, dass in die Abscesshöhle der einfachen oder entzündlichen Bubonen wenige Tropfen einer einpercentigen Sublimatlösung :mittelst der Pravaz'schen Spritze injicirt werden. Die Injectionen müssen wenigstens zweimal in Intervallen von zwei Tagen wiederholt werden. Nach dem Ausziehen der Nadel, die sehr dünn sein muss, wird die Einstichüffnung mit Bruns'scher Baumwolle bedeckt, worauf ein entsprechender Verband angelegt wird. Dornig.

Exstirpation der Drüsen beim sogenannten Bubo hält Heath (3) für indicirt 1. bei den unregelmässigen Ulcerationen mit unterminirten Rändern und allen Zeichen des Zerfalls; 2. bei den chronisch entzündlichen Schwellungen mit Drüsen in den verschiedenen Stadien der Hyperplasie und des Zerfalls mit periglandulärer Induration nnd Eiterung, mit Fistelgängen; 3 . bei den sogenannten indolenten Tumeren; 4. bei alten indurirten, sinuösen Bubonen; 5: beim serpiginösen Bubo; 6 . bei den Drüsenschwellungen im primären und secundären Stadium der Syphilis. Der Eingriff ist nach Heath weder schwierig noch gefahrvoll: er coupirt den weiteren Verlauf der Erkrankung, er verhindert Recidive. Mit scharfem Löffel und Messerstiel ist alles Nekrotische zu entfernen; die unterminirteu 
Ränder müssen mit der Scheere abgetragen werlen. Dic Exstirpation soll so früh als möglich geschehen, gleichviel ob eine Eiterung nachzaweisen ist oder nicht. Alte Fisteln spaltet man und atrt man. Die Exstirpation syphilitischer Bubonen ist nur für gewisse Fälle und Individuen, namentlich scrophulöse, indicirt. Der Hautschnitt soll möglichst in der IJüngsaxe des Gliedes gemacht werden. Nach der Operation selbst empfiehlt $\mathrm{H}$ eath rine Aetzung mit Chlnrzink. Jodoform, antiseptische Gaze, Sublimat-Hol\%wolle und festen Verband. Die tiefe Fascie schützt alle wichtigen Gebilde. Dir von Winslow und $J_{0}$ nes dreimal beobachtete consecutive Gangraena scroti ist nach Heath ein unerhörtes Vorkommniss. Er glaubt eher an eine trophische Ursache (Läsion des N. ilio-inguinalis), als an cine Fortsetzung der Entzündung. Und $\mathrm{Heath}$ erinnert sich hiebei an eine Radicaloperation von einer irreponiblen Hernie: auch hier folgte eine Gaugraena scroti mit tödtlichem Ausgange nach. Die Wunde selbst hatte ein ganz normales Aussehen and granulirte kräftig. Auch hier hïlt $H$ eath eine trophische Stürung nach analoger Nervenverletzung für sehr wahrscheinlich.

Friedheim.

\section{Syphilis. Allgemeiner Theil.}

1. Brouardel. Differential-Diagnose zwischen Schanker und Herpes, ühor Vulvitis aphthosa und diphtherica, über Schwierigkeiten in der Untersuchung. - Gaz. des Hôp., 20 October 1887.

2. Palmer. Periscope of syphilology. - American Practitioner and News, 25. Juni 1887.

3. Fonrnier. Document statistique sur les sources de la Syphilis chez la femme. - La semaine médic. 1887, Nr. 43.

4. Diday. Etats morbides suite de syphilis, non syphilitiques. - Le Bull. médic. 1887, Nr. 50 .

5. Carleton. Commnnicability of Syphilis through the saliva. - British Medic. Journ. Nr. XII, 1887.

6. Moffet E. Communication of Syphilis by tatooing. - Lancet 1887, Nr. 3349, pag. 910.

7. Porter. Communicability of Syphilis through the Saliva. - British Medic. Journ., 10. Decernber 1887.

8. Lewentaner M. Ueber Beschneidungssyphilis. - Monatsh. f. prakt. Derm. 1887, $\mathrm{Nr}$. 20, pag. 904.

9. Dietricl. Die Palpation der Lymphdrüsen. - Aus den Sitzungsberichten der physikal. medic_Societät za Erlangen, 19. Juli 1886.

Brouardel (1) recapitulirt das Schema Fonruier's: er betont am Herpes: 1. die polycyclische Anordnung; 2. die Abwesenheit von Drisenaffectionen; 3. die fehlende Härte des Grundes; 4. die geringe Tiefe der Ulceration; 5. das Jucken, die Kratzeffecte; 6. die mangelnde Contagiosität. Dje Vulvitis aphthosa zeigt eine deutliche l'entenz zur Geschwärbildung wie zur Gangrän. Dasselbe behauptet Brouardel von der Vulvitis diphtheritica: die Vaginalschleimhaut ist ein Prälilectionssitz der Dipltherie. Brouardel erwahnt die Schwierigkeiten, welche durch die Untersuchung venerischer Kranker erwachsen können. B rouardel hïlt eine Uebertragung blennorrhoiseher Secrete, welche mehrjährigen Krankleitsherden entstammen, für absolut unmöglich und wirkungslos. Weiterhin erinnert er an diejenigen Fülle ron Syphilis, in denen das Kraukheitsstudium des Iuficirenden ein viel früheres zu sein scheint, als dasjenige der inficirten Person. Ein solcher Fall kann eintreten, wenn beide Individnen in nicht grossen zeitlichen Abstïnden erkrankten, wenn die Syphilis bei deu einen (zuletzt inficirten) Individuum stürmisch verlänft. Brouardel cütult die Bade- 
schwämme zu den gefülurlichsten Infectionstrïgern der Syphilis. Er spricht über die gewaltsame Schändung, über die extragenitalen Symptome derselben. Je brutaler der Gewaltact ist, je verzweiflungsvoller das Opfer sich wehrt, um so mehr springen jene letzteren hervor. Man findet sie im ganzen selten, dann aber charakteristisch ausgebildet in der Umgebung der Genitalien, an Arm- und Handgelenk, an Knie und Oberschenkeln. Wohl zu unterscheiden sind die bedeutungslosen Pigmentirungen der Inguinalregion. Diagnostisch wichtig sind hingegen die Ecchymosirungen der Hriiste. Brouardel citirt den Fall Tardieu's, in dem der Busen des Weibes von den Zühnen zerfleischt war. Die oberflüchlichen Verletzungen ziehen, falls sie blutig sind, unmittelbar die Blntung nach sich; die tieferen Jäsionen führen oft erst nach Tagen zur deutlichen Wahrnehmung einer Hämorrhagie. Brouardel herührt sodann flüchtig die Blutungen der Simulanten etc., welche zumeist durch Ansaugung entstehen. Er wendet sich zu den Rupturen der Schejde. Solche hält er für möglich cinmal in Folge roher Digitalexploration, sodann bei alteren Frauen, welche geboren haben, als Folge einer brutalen Cohabitation. Den Jungfrauen ist ein Schutz gegeben gegen Vaginalperforation durch die Hemmung im Introitus vaginae, durch die consecutive Abschwächung des Anpralls, den die Scheidenwand durch den Penis erleidet. Hämorrhagien, Metrorrhagien, retro-uterine Hämatocelen, Beckenperitonitiden künnen für einen Gewaltact sprechen. Beim Lustmord findet die Schändung des Opfers theils vor theils nach dem Tode desselben statt: bald sieht man die Spuren der Strangulation, bald Schnittwunden. Ein sicherer Beweis für Cohabitationen intra vitan liegt in Blutungen des Hymen. Von juristischer Bedeutung für den Nachweis von Cohabitationen kann die Auftindung von Spermatozoën innerhalb der Scheide sein; man hat solche noch acht Tage nach dem Tode rler Frau in lebhafter Bewegung gesehen.

Frie dheim.

Palmer (2) lieferte ein Referat über die während der letzten zwölf Monate interessirenden und discutirten Punkte, betreffend die venerischen Krankheiten. In Boston stellten sich, wie Grun ough berichtet, unter 1 ह̈93 in städtischen Hospitälern behandelten Fällen 391 als Ulcer. dura, 219 als Ulcer. mollia, 931 als zweifelhaft und $\mathbf{5 2}$ als Herpes progenital, heraus, also ein Verhältniss, der Ulcer. mollia zu den anderen Processen wie $1: 4$, wïhrend in der Privatpraxis das Verhältniss sich 1:10 stellte. Es stellt sich dabei wiederum eine Abnahme der Zahl der weichen Sehnnker heraus. Dr. Arthur stellte aus der militär-ärztlichen Praxis durch Beobachtung an 33.000 Menschen während zehn Jahren einundvierzig Fälle von Entstehung des Primäraffectes auf secundärem Wege zusammen; in zwölf Fällen von Lippenschanker glaubt er an directe Uebertragung von der Vulva. Es folgt die Erörterung der Fournier'schen Frage: Kann der Vater das Kind inficiren, die Mutter aber gesund bleiben? Ferner wird erörtert: die Beziehung der Syphilis zur Eheschliessung. Ein grosses Interesse wendet man der Behandlung der Gonorrhöe zu. Dje Entfärbung des Gonococcus durch die Gram'sche Methode, wie sie Roux jetzt wieder als Kriterium aufgestellt hat, wird besprochen. Als bestes Mittel empfiehlt sich warme Irrigation mit Sublimatlösung und Borsäure; auch Hydronaphthol und Thallin sulf. werden als Ansiseptica gerühmt. Dr. Brever verlangt für die Belandlung einer frischen Gonorrhüe zwei Wochen, eine Zeit, die durch zweckmüssige, hygienische Massregeln noch verkürzt werden kïnne. Die ZahI der Complicationen ist bei der Behandlnng mit reichlicher Irrigation bedeutend vermindert. Vor der Urethrotomie empfiehlt sich die innerliche Verabreichung von $0.6 \mathrm{Gr}$. Acid. boric., um den Urin steril zu machen.

Löwenhardt. 
Fournier (3) gibt, um zu zeigen, wie gross der Percentsatz der "Syphilis des innocents" ist, eine sorgfältige Statistik über 887 luetische Frauen seiner Privatpraxis, über die er genauere Aufzeichnungen gemacht hat. Darunter sind 8:42 Fälle von auf sexuellem Wege acquirirter Lues, 4.) (also fünf Percent) von anderweitiger zufälliger Infection (sieben hereditäre Lues, vier zufällige Infection im Kindesalter, acht durch Sünglinge inficirte Ammen, fünf bei Ausübung ihres Berufes angesteckte Hebammen, zwölf Infectionen durch Ammen, Dienstmädchen etc., zwei durch Vaccination, zwei durch Katheterismus der Tuba Eustachii, einer durch Nothzucht, vier auf unbekanntem, aber sicher nicht geschlechtlichem Wege erworbene). Von den 842, durch sexuellen Verkehr inficirten Frauen waren 220 verheiratet; auf Grund einer sehr sorgfältigen Beachtung aller - bei solchen Aufzeichnungen natürlich sehr grossen - Fehlerquellen berechnet Fou rnier, dass 19-20 Percent aller dieser Frauen in der whe durch ihre Gatten inficirt seien; er betont, dass diese Zahl ein - sicher zu kleines Minimum sei, zu dem jedenfalls noch die fünf Percent der zufälligen Infectionen hinzuzurechnen seien. Also in der Privatpraxis Fournier's kamen auf 100 syphilitische Frauen 2'-25 "ohne Schuld" inficirte. Mit Recht hebt der Verf. hervor, dass diese abschreckend grosse Zahl, über die er selbst erstaunt gewesen ist, in der That auch Diejenigen auf die Nothwendigkeit sorgfïltigster Prophylaxe hinweisen müsse, welche noch auf dem Standpunkte ständen, dass die Lues eine verdiente Strafe für Ausschweifungen sei.

Jadas ohn.

Diday (4) bespricht die von Fournier als "recidivirender Herpes an der Zunge Syphilitischer" beschriebene Erkrankung. Verf. hat diesen Herpes schon vor längeren Jahren beschrieben, aber inzwischen seine Meinung über die Unschädlichkeit aufgegeben, da er in zwei Fällen die specifische Natur der Affection durch Uebertragnng auf die Frauen der betreffenden Kranken constatiren konnte. Verf. hält die Erkrankung nicht für einen echten Herpes und meint, dass in solchen Fällen die Heirat nicht zu gestatten sei.

Jacobi.

Carleton (5) publicirt einen Fall von Syphilis-Uebertragung durch den Speichel, der demjenigen von Porter (British Medical Journal, 10. December 1887) analog ist. Es handelt sich um eine Tüttowirung. Der Operateur. war im tertiären Stadium der Syphilis. Der Tättowirte bekam zwei Schanker auf den tättowirten Vorderarmen. Ein Bubo axillaris vereiterte, bevor die localen Symptome an den Armen hervortraten. Der Operatenr hat, wie man sicher beobachtete, mehrmals anf die Arme bei dem Acte selbst gespieen, wahrscheinlich, um das Blut mit dem Speichel abzuwischen. Die antispecifische Cur des Tättowirten war erfolgreich. Friedheim.

Moffet (6) berichtet über drei Fäle von Uebertragung von Syphilis durch Tättowirung. Bei allen drei Patienten, Soldaten, war frühere Infection ausgeschlossen, und ein typischer Primüraffect auf der Tättowirungsstelle mit sich anschliessenden Allgemeinerscheinungen vorhanden. Sehr merkwürdig erscheint die bei allen Fällen auffallend lange Incubationszeit (circa fünf Monate); Moffet will diesen Umstand durch Nichtbeachtung der ersten Symptome erklären.

Arning.

Porter (7) erzählt folgenden Fall von Syphilis-Uebertragung durch den Speichel. Ein englischer Corporal wurde im Hospital zu Dover wegen zweier Ulcerationen des linken Vorderarmes behandelt. Eine Woche vor der Entlassung liess er sich von einem Kameraren, der nachweislich syphilitisch war, tättowiren. Die Vorderarm-Geschwüre vergrösserten sich; sie 
zeigten keine Tendenz zur Heilung; sie glichen schliesslich Schankergeschwüren. Die Axillardrüsen schwollen gross und lıart an. Ein charakteristisches Exanthem folgte nach. Der Patient gab an, dass sein Kamerad, der ihn tättowirte, wiederholt bei diesem Act auf seinen Arm gespieen und den Speichel auf letzterem rerrieben habe, um das Blut abzuwischen. Der Patient wurde antisyphilitisch behandelt. Der Erfolg der Therapie war langsam eintretend, aber deutlich. Die constitutionelle Erkrankung des Inficirenden war durch das Hospital, in dem er frïher antisyphilitisch behandelt worden war, sicher constatirt.

Friedheim.

Is ew entaner (8) berichtet über einen äusserst fragmentarisch beobachteten Fall, von welchem es dem Verf. nicht zweifelhaft ist, dass es sich um acquirirte und zwar durch die Beschneidung übertragene Syphilis handelt, während dem Ref., soweit es nach den wenigen mitgetheilten Erscheinungen zut beurtheilen ist, nicht einmal die Diagnose Syphilis festzustehen scheint.

I esser.

Dietrich (9). Die unter Prof. Penzoldt angefertigte fleissige Arbeit, welche, obwohl statistischer Natur (die zahlreichen Tabellen müssen im Original nachgelesen werden), durch die überraschenden Resultate durchaus nicht trocken erscheint, sondern in hohem Grade anregend wirkt, behandelt im I. Theil die Palpation der IJymphdrüsen bei Gesunden. Bei 439 Gesunden (Soldaten and Realschülern) fanden sich in 99 Percent palpable Drüsen, und zwar waren palpabel Occipitaldrüsen in $2.2 \mathrm{Per}$ cent, Halsdrüsen (Cervical- und Supraclaviculardrüsen) in $79 \cdot 4$ Percent, Axillardrüsen in $72 \cdot 4$ Percent, Cubitaldrüsen in 82.6 Percent und Inguinaldrüsen in 92.9 Percent. Auch wenn man diejenigen Fälle ausschaltet, wo begleitende Hautaffectionen (121 Fälle) vorhanden waren, and diejenigen, die einige Zeit vor der Untersuchung eine Krankheit überstanden haben (98 Individuen), Verhältnisse, die auf die Drüsenvergrösserung vielleicht von Einfluss waren, so waren bei den restirenden 220 gesunden Individuen immer noch in denselben obigen Percentsätzen Drüsen fühlbar. Soviel steht also fest, dass fast alle gesunden Menschen in irgend einer Körperregion palpable Lymphdrüsen haben. Inguinal-, Cubital- und Halsdrüsen sind in der Mehrzahl der Fäle beiderseits vorhanden, Axillardrüsen eben so oft einseitig als doppelseitig, Occipitaldrüsen meist einsejtig. Kinder bis zum zwölften Lebensjahre zeigen hänfiger palpable Drüsen als Erwachsene. Die Anzahl der in den verschiedenen Körperregionen palpablen Drüsen ist an den Stellen am grössten, wo überhaupt die meisten Lymphdrüsen liegen, sie nimmt übrigens mit dem zunehmenden Alter ab. Ihre Grösse ist unabhängig vom Alter, durchschnittlich linsenbis bohnengross. Der Il. Theil der Arbeit beschäftigt sich mit der Palpation der Lymphdrüsen bei Syphilis (und Diphtherie, welch letztere wir hier übergehen). Unter 50 Patienten mit florider, secundärer Syphilis hatten palpable Occipitaldrüsen 8 Percent, Halsdrüsen 98 Percent, Axillardrüsen 90 Percent, Cubitaldrüsen 72 Percent und Inguinaldrüsen 100 Percent; im Vergleich zu Gesunden ist also der Percentsatz der überhaupt fühlbaren Lymphdrüsen erhöht, auch ihre durchschnittliche Zahl in den einzelnen Regionen und ihr durchschnittliches Volumen ist, wie weitere 'Tabellen zeigen, erhöht. Dagegen ist - entgegen der Annahme der meisten Autoren, conform aber der Ansicht Bäumler's - die Cubitaldrüsenschwellung nicht charakteristisch für allgemeine Syphilis, da weder die Anzahl noch die Grösse der Cubitaldrüsen bei Syphilis vermehrt gefunden wurde; ja es fanden sich sogar dieselben (wohl zufallig) seltener palpabel bei Iuetischen als bei Gesunden. 


\section{Syphilis. Haut und Schleimhaut.}

1. Cant. Clinical observations on "Induration" in the primary lesion of syphilis in Women. - Medien Chirurgical Transactions 1887.

2. Monre E. J. Sur un eas de chanere induré de la fosse nasale droite. - Bullet. gén. de thér. 9, 1887.

3. Sherwell. Duuble chancre of the nipple. - Journ. of cut. and grnitourin. dlis. $1887, \mathrm{Nr} .8, \mathrm{p} .311$.

4. Balzer. Végétures syphilitiques. - Ia semaine médicale $1887, \mathrm{Nr} .44$.

3. Salsotto $G$. Di una forma non ancora descritta di sifilide cutanea. Giorn. ital. delle mal. ren. e della pelle 1887, 5 .

6. Horand M. Syphilide acnéique du nez. - Iyon médieal Nr. 42, 1887.

6a. Ehrmann. Uober die Hantentfürbungen im Frühstadium dar Syphilis. - Internat. klin. Rundschau, 1887, 27 - 33.

7. Klotz Hermann G. On the nceurence of ulcers rosulting from spontancons gangrene of the skin during the later stages of syphilis, and their relation to syphilis. - New-York Medical Journal 1887, Nr. 13, pag. 39\%.

Die Inluration als Symptom des syphilitischen Primairaffectes ist nach Cant (1) bei Frauen im Ganzen weniger hïufig und weniger deutlich ausgebildet, als bei Männern. Das Verhïltniss ist ungefïhr derartig, dass in einem Drittel der Fäle die Induration sehr dentlich, in cincm zweiten Drittel nur mässig stark, im letzten Drittel aber fast gar nicht mehr wahrnehmbar ist. Die syphilitische Induration beim Weibe besitzt durchaus nicht immer jene auf die Basis des Primäraffectes beschränkte, von der Umgebung scharf abgegrenzte Loealisation. Die Masse des Infiltrats nimmt zu von der dünnen Pergamentsklerose bis zu müchtigen Tumoren. Die Sehwere der constitutionellen Erkrankung ist ganz unabhängig von diesen Differenzen. Die Induration beim Wuibe ist oft eine progressive Infiltration nach $\mathrm{Cant}$; der typische $H$ unter'sche Knoten ist beim Weibe selten. Am wenigsten ist die Induration ausgebildet an den Primüraffecten des Orificium vaginale. Die Verdickung tritt ein vom vierten bis vierunddroissigsten Tage an nach Ausbillung des Geschwürs. In einem Falle beobichtete Cant sieben lage nach Heilung des initialen Geschwürs selbst liv: Verdickung nur in der Umgebung desselben. Der histologische; Charakter des /ellinfiltrats ist meist derjenige einer chronischen nder subacuten, selten ciner acuten Affection. Die Verhärtung ist am deutlichsten auf der Höhe der Geschwürsbildung, sehr oft in der zweiten Hälfte der Ulcerationsperiode oder später selbst. Die Frage, ob jeder syphilitische Schanker hart sein muss, bcantwortet Can t dahin, dass ausgesprochene Induration ebensowinig den specifischen Charakter der Affection beweist, als eine fohlende Incluration einem primären Geschwüre denselben raubt. Friedhoim.

Bei dem höchst seltenen Sitz des Primäraffectes in der Fossa nasalis ist die Mitheilung von Spencer Watson, welcher über eine einunddreissigjihrige durch einen luetischen Sïugling inficirte Amme berichtet, von Interesse. Der Schanker sass an der Innenseite des linken Nasenflügels und der Fall hatte grosse Achnlichkeit mit dem von Moure (2) beobachteten Patienten. Der rechte Nasenflügel ist durch das 2 Ctm. breite, dem Septum anfsitzende Uleus abgehoben. Bei dem Infectionsmodus sui jedenfalls zu berücksichtigen, dass ausser der directen Uebertragung durch sexuelle Exeesse noch an die Möglichkeit der Ansteckung dureh den Finger zu lunken ist, mit dem Pationt dic Gewolnheit hatte, sich die Nase zu reinigen. Differentialliagnostisch hebt Verfasser im Gegensatz zum Sarkon ete. herror, dass die Drüsenschwellung charakteristisch sei und 
frühzeitiger eintrete. Der Erfolg der antisyphilitischen Therapie wird schliesslich in zwoifolhaften Fïllen entscheiden mässen.

Lowenhardt.

Sherwell (3) berichtet über einen doppelseitigen Schanker der Brustwarze, dor durch das Säugen eines hereditïr-syphilitischen Kindes entstanden ist.

I c esser.

Balzer (4) berichtet uber zwei Fülle von syphilitischen Striae, die er in einem Fall bei ciner Gravida, im anderen, ohne dass Graviditit bestani, beobachtet hat. Diese Striae charakterisiren sich dalurch, dass sie an den Stellen, an welehen vorher cin papuloses Fxanthem bestand, auftreten und unterscheiden sich von den striae gravilarum durch ihre runde Form und ihren Sitz. - In der sich hieran anschliessenden Debatto in der "Société médicale des hôpitaux" wollen Millard, Guyot und Lallier fïr diese "Narben" die Bezeichnung Striac nicht gelten lassen. Merklen meint, dass sic mit den von Fournier sngenannten "maculae atrophicae" identisch sind.

Jacobi.

Salsotto's (5) Arbeit hat cine, wic er glaubt bisher noch nicht beschriebene syphilitische Hautmanifestation zum Gegenstande, dic ihren Sitz ansnahmslos im Gesichte hat und zwar an den Wangen, Nasenflügeln und Lippen, am häufigsten jedoch längs der Nasolabialfalten und im Sulcus mentolabialis. Dieses Syphilid besteht in schwach crhaltenen, hirsekornbis linsengrossen Papeln von kupferrother Farbe. Sitzen sic in den erwilhnten Hautfalten, so zoigen sic eine lineare Anordnung, die der Richtung der Falten selbst folgt; in diesem Falle confluiren sie wohl auch und bilden dann etwas erhabene Leisten von homogenem Aussehen. Die Papeln berlecken sich alsbald mit dünnen Schuppen, welche sich rasch abstossen, um einer neuen Schuppenbildung Platz zu machen. Die Desquamation hält bis zum totalen Schwinden des Syphilides an, dessen früherer Sitz noch für lüngere oder kürzere Zeit durch einen mehr weniger intensiv gefürbten kupferrothen Flcck markirt bleibt. Salsotto schlïgt für dio in Rede stehende luetische Erscheinung den Namen "papulo-squamöses Gesichtssyphilid“ vor. Unter 300 weiblichen Kranken beobachtete er dieses Syphilid dreiundlünfrigmal, d, i. ein Verhältniss von 10.6:100; bei Männern sah er es niemals. Alter, Constitution and Hantcolorit der Kranken scheinen darauf keinen Einfluss zu üben. Dis papnlo-sqamöse Gesichtssyphilid zeigt sich stets in der Frühperiode der Syphilis, in der Regel im ersten Jahre der Infection. Salsotto glaubt sich zu der Annahme berechtigt, dass dic von ihm beschricbene luetische Manifestation eine besondere Form der Hautsyphilis darstelle und nicht als eine zufïllige Localisation der Syphilis cutanea papulosa im Gesicht aufzufassen sei - cine Ansicht, die jeder stichhältigen Begrinlung entbehrt.

Dornig.

Horand (6) bringt aus der Zahl von dreizehn Beobachtungen ciner syphilitischen Erkrankung der äusseren Haut der Nase zwei Falle, einen bei einem Manne von achtunddreissig Jahren, der fünfzehn Jahre vorher syphilitisch inficirt war und einen zweiten bei einer Frau von zweiundfünfzig Jahren beobachteten, bei welcher die Zeit der syphilitischen Infection nicht genau bestimunt werlen konnte. Verfasser beschreibt diese seltene, von ihm innerhalb achtzehn Jahren nur dreizehnmal beobachtete, immer flem Spätstadium angehörige Erkrankung folgendermassen. Es ontwickehn sich auf der äusseren Haut der Nase, selten auf den Wangen und der Oberlippe Acnepusteln, dio entweder mit Eiter gefüllt oler von schwärzlichen Borken bedeckt sind. Sie stehen entweder vereinzelt ohne irgend welche Anordnung, oder confluiren und bilden grössere Geschwürchen. 
Zwischen ihnen finden sich nach längerer Zeit Narben, die an Blatternarben erinnern und von geheilten Pusteln stammen. Die Nase erscheint im Ganzen geröthet und etwas angeschwollen, ist dabei aber immer schmerzlos. Ein Uebergreifen auf die Schleimhaut findet niemals statt, ebensowenig wie eine Anschwellung benachbarter Lymphdrüsen. Sehr charakteristisch für diese Erkrankung ist, dass sie jeder localen Behandlung hartnäckig widersteht, dagegen einer specifischen Cur sofort weicht. wie dics in den vom Verfasser behandelten Fällen geschah, die nach kürzerem oder längerem Gebrauch von Jodkali vollständig heilten. Die Differentialdiagnose zwischen Acne syphilitica und Acne rosacea, Acne indurata, Impetigo, Iupus und Cancroid der Nase ist nicht sehr schwierig, wenn man die Entstehung, den Sitz und die Beschaffenheit der Pusteln, sowie vor allen Dingrn die Erfolglosigkeit aller Heilverfahren, mit Ausnahme eincr antisyphilitischen Behandlung in Betracht zieht.

Jacobi.

Ehrmann (6a) hat bei der mikroskopischen Untersuchung des I eukoderms gefunden, dass eine grosse Anzahl der Infiltrationszellen in den Papeln mit Pigment versehen ist und dieses in die Epidermis transportirt; in den spateren Stadien gehen die an der Grenze des Papillarkörpers und des Fpithels gelegenen sternförmigen Pigmentzellen zu Grunde und versorgen die Epidermis nicht mehr wie gewöhnlich mit Pigment; ist so die letzte pigmentfrei geworden, so erscheint die betreffende stelle weich, auch wenn in dem Corium sich noch Pigment vorfindet. Bei den hüheren Stadien der luetischen Infiltrationen schwinde in Folge der daraus resultirenden Circulationsstörung das - normalerweise aus den rothen Blutkörperchen entstehende - Pigment. Bei den stärker papulösen Syphiliden soll nach den Untersuchungen des Verfassers das Keratohyalin schwinden und in Folge dessen eine schiefergraue Färbung auftreten.

Jad assohn.

Klotz (7) hat in einigen Fallen von Spätsyphilis das Entsteben meist recht ansgedehnter Vlcerationen an den unteren Extremititen beobachtet, ohne dass gummise Neubildung vorausging. Vielmehr entstand ohne alle Schwellung ein dunkelgrüner Fleck, der 'sich allmälig in einen Brandschorf verwandelte, ablüste und ein scharfrandiges Geschwür mit flach em $R$ ande, dunkelgrünem unebenen Gunde und seröser übelriechender Secretion zurückliess, welches demnach mehr einem Ulcus chron. cruris simplex, als einem syphilitischen Geschwür ähnelte. Stets bestand dabei bedeutendes Oedem der Extremität nebst beträchtlichen Schmerzen. Die antisyphilitische Therapie erwies sich in zwei Fallen als machtlos; in dem einen derselben erfolgte Tod durch Sepsis, der andere lebt noch, ist aber dauernd unfühig seine Beine zu brauchen; bei einem dritten endlich trat völlige Genesung ein. Verfasser hält, wohl mit Recht, das Krankheitsbild für das einer spontanen $G$ angrän und vermuthet als Ursache Endarteriitis obliterans syphilitica. Dass die antisyphilitische Behandlung wenig oder nichts nützte, erklärt sich alsdann daraus, dass es sich hier eben nicht um Syphilis selbst, sondern um eine Folge der Gefïssverstopfung handelte. Verfasser bedauert, dass er nicht durch eine (Obduction seine Vermuthung bestätigen kann, und will eben daram durch diesen auf dem internationalen medicinischen Congress zu Washington gthaltenen Vortrag die in jener Bezielung besser gestellten Collegen auf solche Fälle aufmerksam machen.

Block.

\section{Viscerale Syphilis.}

1. Aikmun John. Illustrations of syphilitic disease in the nervous system. - Glasgow Medical Journal, October 1887, pag. 258. 
2. Guder. Beiträge zur Aetiologie der Geistesstörungen. - Aus dem Bericht über die Pommersche Provinzial-Irrenanstalt bei Ueckermünde $1875-1887$.

3. De Renzi E. La sifilide dei centri ncrvosi. - La riforma med. 1887, 45.

4. Bianchi L: Patogenesi della tabe con speciale riguardo alla sifilide. - Giorn. internaz. d. sc. med. 1887. (Ref. Giorn. ital. delle mal. ven. e della pelle $1887,4$.

5. Nenmann H. Zur Frage uber die Beziehungen zwischen Tabes und Syphilis (ans dem städtischen Krankenbaus Muabit in Berlin). - Berliner klin. Wochenschr. 1887, Nr. 43.

6. Naegeli. Ueber die Beziehungen der Lues zur Tabes dorsalis. - Inaug.Dissertation, Zürich 1887.

7. Bauer. Syphilitic Apoplexy etc. - The internat. Medic. and Surgic. Synopsis, Vol. 1, Nr. 2, October 1887.

8. Hobbs A. G. (d'Atlante, Georgia A. U.) Denudation des faisceaux antérieurs de la moëlle consécutive à une ulcération syphilitique du pharynx. - Annal. des malad. de l'oreille ete. T. XIII, Nr. 10, 1887.

9. Schmick. Ueber einen Fall von chronischer syphilitischer Leptomeningitis cerebralis. - Inaug.-Dissertation, Berlin 1887.

10. Laudet $R$. Des hémiatrophies de la langue dorigine syphilitique. Annal. des malad. de l'oreille etc. T. XIII, Nr. 12, 1887.

11. Buck Albert $H$. A case of rapid and almost total loss of hearing in a child, seven years of age; inherited syphilis apparently the cusse; marked improvement following the use of the iodide of potassium. Medical Record 1887, pag. 453.

12. Gradenigo G. Zur Lehre der primären Otitis interna. Die Otitis interna bei hereditärer Syphiljs. - Arch. f. Ohrenheilkunde XXV. Bd., 3. u. 4. H., 1887.

13. Theobald. Affection syphilitique du labyrinthe. Compte rendu de la société d'otologie d'Ámérique. - Rev. mensuelle de laryngol. etc. 8. année, $\mathrm{Nr}$. $10,1887$.

14. Holm. Nogle Tilfaelde of anosmia syphilitica. - Hospitals-Tidende 1886, Nr. 27.

15. Massei. Due noteooli casi di aderenza del velo alla parete faringea. - Suppl. della gazz. degli ospitali 1887, 2.

16. Scaremzio Angelo. La iritide sifilitica considerata quale sintoma tardivo anzichè di ricaduta della sifilide. - Giorn. ital. delle mal. ven. e della pelle 1887. 4 .

17. Lneas Robert. Case of syphilitic gumma situated in the trachea successfully treated by large doses of iodide of potassium. - British Medical Journal, Dec. 2\%, 1887, N. 1408.

18. Curtin Roland G. The influence of sea-air on syphilitie plithisis. (Der Einfluss der Seeluft auf syphilitische Phthise.) - Philadelphia med. Times Vol. XVIII. N. 522.

19. Fraenkel Eug. Ueber Tracheal- und Schilddrüsen-Syphilis. - Deutsche med. Wochenschr. 1887, Nr. 48, pag. 1035.

20. Sokolowski A. Ueber syphilitische Verengerung der Trachea und der Bronchien. - Gazeta Lekarska 1887, Nr. 35 u. 36.

21. Heller A. Die Iungenerkrankungen bei angeborener Syphilis. Deutsches Arch. f. klin. Medicin, Band 42. Heft 1-3.

22. Devic. De la syphilis du poumon. - Province médicale, 10., XII, 1887.

23. Sehuchter F. Ueber das Verhalten der Milz und Niere bei frischer Syphilis. - Wiener med. Blätter Nr. 41 u. 4z, 1887. 
24. Tommasoli. Contributo allo studio della milza in rapporto colla sifilide. - Gazz, degli ospitali 1887, 89.

23. Mauriac Ch. Diagnostic et pronostic du sarcocèle syphilitique. Gaz. des hópit. Nr. 131. 1887.

26. Jïger. Zwoi geheilte Fälle von syphilitischer Pseudo-Paralyse. - Revue mensuelle des malad. de l'enfance 1887, Juli, pag. 322 u. f.

27. Cazin et Iseoveseo. Des rapports du rachitisme avec la Syphilis. (Memoire couronné par l'Académie de médecine, prix le lhygiene de I'enfance. - Arch. gén. de méd. 1887, Sept., Oct., Nov.

28. Suckling. Syphilitic Epiphysitis. - British Madical Journal, 24, XII., 1887.

29. Fschle. Beiträge zur Casuistik der syphilitischen Dactylitis. - Langenbeck's Archiv, Bd. XXXVI, 2.

30. Sakotski. Chronic glinders simulating Syphilis. - Lancet 17, XII, 1887.

Aikman (1) berichtet etwas unklar über drei Faile, die er als typisch für die Syphilis des Nervensystems bezeichnet. Bei dem ersten. ciner vierzigjührigen Patientin von licderlichem Lebenswandel mit syphilitischer Anamnese. begann die Kranheit mit Kopfsehmerz. bald zeigten sich Zeichen von Verrücktheit, Paralysen und Paresen verschiedenor linksscitiger Nuskelgruppen, besonders stark am linken trme ansgebildet, Fehlen des Kniephänomens beiderseits und totale Incontincnz der Blase und des Rectum. Verf, vermuthete eine Affection der Hirnarterien, olne sich über deren Localisation zu änssern, und sah von Joulkali ( $6 \circ \mathrm{Jd}$. pro die) schnellen Erfolg. - Dass in dem zweiten Falle selbst die strengste antisyphilitische Cur nichts half, erscheint selbstverständlich, di sich derselbe nach des Verf. eigener Schilderung als Tabes dorsalis darstellt, die man, auch wemn der Patient einmal syphilitisch war, doch nicht schlechtweg als Nervensyphilis bezeichnen darf. - Vom dritten Falle wird erzählt, dass der Patient, ein Militärarzt im indischen Dienst, durch angebliches hlimatisches (Peschawer-) Fieber und Chiningtbrauch zum skelet abgemagert war und insbesondere Atrophie der linken Extremititen aufvies. Verf. vermuthete gleich Syphilis (?), Fingerinfection wurde zugestanden, und in der That verschwand unter Jodkaligebrauch das Fieber und die Erniburung hob sich sichtlich.

Block.

Guder (2) hat das Actenmaterial von 1200 Geisteskranken der Ueckermünder Anstalt durchgesehen, und von somatischen Ursalchen, ausser auf die acut-fieberhaften Erkrankungen auf Lues geachtet. Er fand dieselbe bei 18 Frauen und 36 Münnern, es sind aber hier nur diejenigen Fialle berücksichtigt, in denen schon in der Anamnese Lues ansilrüeklich erwähnt war. Es entspricht also die Zahl durchaus nicht den wirklichen Verhältnissen, zumal dio Animnese bei vielen früher vagrabundirenden oder ans Correctionsanstalten stanmenden Kranken nur mangellibft war. abgesehen noch davon, dass sie anfgenommen wurte zu einer Zeit, in der der Frage nach Lues im Vorleben weniger Aufmerksamkeit guchenkt wurle. Unter diesen $\ddot{34}$ syphilitischen Kranken befanden sich 4:) Paralytiker (10 weibliche und 35 männliche). Da im Ganzen in dem betreffenden Zeitranme 40 Frauen und 1033 Männer wegen Paralyse aufgenommen wurden. so "rgibt sich also bei 25 resp. 23 Porcent Lues. - Die antisylhilitische Behindlung ist in keinem Falle von Ertolg gerresen. - Eine duzahl kurgetiaster Krankengeschichten ist beigegeben.

Kohn.

De Renzi (3). Die Localisation der Syplilis im Centralnervensystem lässt sich in der Regel auf bestimmte prädispunirefide oder occasionelle IIomente zurückführen, die mit der luetischen Infection in keinem directen 
Zusammenhange stehen. Dahin gehört vor Allem eine neuropathische Constitution, ferner Hirncongestionen in Folgo gesteigerter Hirnthïigkeit. wie z. B. bei angestrengter geistiger drbeit, dann Kupftraumen, der Alcoholismus und kalte Bäder (sic!). Was die Therapie der Hirnsyphilis betrifft, empfiehlt Verf. in erster Linie das Quecksilber in Form von Finreibungen. oder Injectionen, ferner Dampfbïler zur Erzielung einer rejchlichen Diurese, Jodkali und als Nachcur Thermal- und Mineralbäler.

Bianchi (4) zieht aus einer längeren Beobachtungsreihe von Tabes: fällen den Schluss, dass die Syphilis nur eine indirecte und mittelbare Ursache der Tabes dorsalis sei, besonders dann, wenn die Kranken hereditär neuropathisch sint.

Dornig.

Neumann (5) fand unter 861 meist dem Arbeiterstande angehörigen männlichen Kranken 147, also 17.2 Percent, welche angaben, in Laes oder Ulcus molle gelitten zu haben; unter diesen waren wieder 76 , also 8.8 Percent, bei denen sicher oder schr wahrscheinlich secundäre Syphilis vorhanilen gewesen ist. - Unter den sämmtlichen 861 Kranken waren 17 Tabesfialle $=2 \cdot 0$ Percent, unter den $1 \dot{\prime} 7$ nit weichem viler hartem Sehanker Inticirten 12 Tabesfäle $=8.2$ Percent, unter den 76 sicher Syphilitischen befanden sich 9 Tabische $=11.8$ Percent. - Cnter 20 Tabesfällen (zu den obigen 17 kamen noch 3 hinzu, die ausserhalb der fortlaufenden statistischen Erhebung standen) fand Verf. 13 mit Schanker $=65$ Percent, von denen 10 sicher syphilitisch waren; also 50 Percent Syphilis bei Tabes.

Naegeli (6) hat bei 46 Tabikern aus der Praxis von Prof. Bern$h$ ardt (Berlin). die in Bernhardt's Arbeiten über denselben Gegenstand noch nicht verüffentlicht sind, 60 Percent Luetische gefunden, also dieselbe Zahl, za der Bernhardt in seineu früheren Publicationen gelangt ist. Dagegen fand Verf. unter 150 Patienten, die nicht tabisch und nicht manifest syphilitisch waren, nur 5.3 Percent sicher Lactische und 11.3 Percent Verdächtige, höchstens also $16 \cdot 6$ Percent. - In einer überaus fleissigen Zusammenstellung der gesammten Literatur über die betreffende Frage (das Literaturverzeichniss umfasst $\because 11$ Nummern) fand Verf, in 1403 bisher veröffentlichten Tabesfällen 46.1 Percent sicher Luetische, 14.5 Percent auf Lnes Verdachtige, zusammen also $60^{\circ} 6$ Percent. Im Gegensatze hierzu fanden sich unter den bisher veröffentlichten 1450 Nicht-Tabikern, die auf frühere Syphilis geprüft wurden, nur $9 \cdot 5$ Percent sicher Luetische und 12.7 Percent Verdächtige, zusammen also nur $22 \cdot 2$ Percent. Kohn.

Bauer (7) berichtet über fulgenden Fall: Ein vierundzwanzigjähriger Mann, der ein Jahr vorher eine Initialsklerose atequirirt liatte, bekim plötzlich cine selur schwere Apoplexie; er war zwei Wochen komatös, dabei Lähmung der ganzen rochten Seite; Incontinentia urin. et alv. - Sogleich Einleitung einer Schmiereur; nach vierzehn Tagen auch Jodkali; nach Rückkehr des Bewusstseins zeigte sich, dass der Patient total muarotisch und aphatisch war. Nach sechs Wochen war nur ein Gediuchtnissdefect für gewisse Worte und Begebenbeiten zu constatiren; nach 3 Munaten war der Patient total geheilt. - Wilhend seiner Krankheit gebar seine Frau congenital-luetische Zwillinge - sie selbst soll bis jetzt (drei Jahre lang) vollständig gesund geblieben sein.

Jadassohn.

Hobbs (8) find bei einem jungen Ochsenhirten aus Texis, der angeblich nie syphilitisch inficirt war, ein grosses Geschwür im oberen 'Theile der hinteren Rachenwand. Verf. entfernte mehrere kleine Fonochenstückchen und konnte dann mit seinen Zeigefingur bis zur ersten Phalanx 
in eine tiefe Höhle eindringen, ohne auf Knochen zu stossen. Der Kranke klagte über Abmagerung, Schlaflosigkeit, constanten Schmerz im Hinterkopf und hält den Kopf nach der einen Seite geneigt. Während einer localen Behandlung der Wundhölle (Application von Höllenstein in die gut gereinigte Höhle) bekam der Kranke plötzlich eine Lähmung der rechten Körperhälftc ohne Bewusstseinsstörung. Dic Lähmung dauerte cine halbe Minute, dann kehrtc unter dem Gefühl eines Frémissement die Beweglichkeit wieder. Der gleiche Lähmungsanfall wurle in ähnlicher Weise noch einmal auf der linken Seite hervorgerufen. Zwei Wochen spater, als die Heilung durch den Gebrauch von Jodkali und entsprechender Localbehandlung bereits vorgesehritten war, traten beim Auswischen der Höhle mit Watte Zuckungen der Extremitäten ein; später wurde dirch Druck nur das Kriebelgefühl (Frémissement) erzeugt. Bei den hemiplegischen Anfällen hatte Verf. auch Erweiterung der Pupillen beobachtet. Nach längerer Behandlung vollige Heilung. Verf. glaubt, dass das Rückenmark blossgelegen habe und dass durch die Manipulationen in der Wundhöhle vielleicht ein lockeres Knochenstück gegen das Rückenmark gedrückt worden sci.

Kayser.

Der interessante Fall aus der Abtheilung Luichtenstern's in Köln, über den Schmick $(9)$ ausführlich berichtet. verlief folgendermassen: Patient, der Lues leugnet, litt seit 1870 an häufig exacurbirenden Kopfschmerzen, seit 1885 an einer zu vollständiger Amaurose sich steigernden Herabsetzung des Sehvermögens; dabei normale Pupillenreaction, „Hippus“, hochgradige Stauungspapille mit beginnender Atrophie, sthwankender Gang, zuerst sehr verminderte, dann aufgehobene Patellarrefiexe; anfallsweise (nur drei Mal) sehr heftiges Erbrechen mit Convulsionen; endlich (A ugust 1886) sehr intensive Steigerung der Kopfschmerzen. Fieber, häufiges Erbrechen, Nackenstarre - Pupillarreflex noch erhalten - Tod nach acht Tagen. Die Section ergab Hydrocephalus internus, starke Hervorwölbung des dritten Ventrikels, durch die das Chiasma plattgedrückt war, schwache eitrige Infiltration der Pia an der Basis; starke fibrüs schwartige Verdickung der Pia im Bereiche der Art. fossae Sylv. und der Art. communic. post. und chorioid., dadurch Druck auf die Pedunculi und besonders die 'Tractus optici. Die stärkste dieser - mit eingesprengten käsigen Herden versehenen - Platten liegt auf der Tela chorioid. des mittleren Ventrikels, die Vena Galeni stark comprimirend und dadurch den Hydroceph. int. bedingend; Ependymitis granulosa an der Oberfläche des Corpus striat. und Thalam. opticus. Rü ckenmark normal. Die mikroskopische Untersuchung ergab, dass diese Platten überall im Anschluss an die Gefässe entstanden waren; die Intima und vor Allem die Adventitia der letzteren stark verdickt und zum Theil hyalin degenerirt. Im Chiasma hochgradige Degeneration der Nervenfasern, obenan die Tractus optici; die Optici selbst wurden leider nicht genauer untersucht. Verf. deutet diesen Befund als das Resultat einer chronisch syplilitischen, fibrös-kïsigen Meningitis, zu der eine acute eitrige Basilameningitis getreten war; ohne auf diese Frage näher einzugehen, behauptete er, dass diese Affection syphilitischer Natur gewesen sei und dass der acut-eitrige Process sich angeschlossen habe, wie Hautgummata ete. vereitern - ein Inalogieschluss, welcher, in dieser Weise ausgesprochen, wohl keine allgemeine Billigung finden wird. In sehr ansführlicher Weise wird dann das Zustandekommen der einzelnen nervösen Störungen aus dem Sectionsbefunde heraus analysirt und zu erklären versucht.

Jadassolin.

Laudet (10) berichtet über folgende zwei Beobachtungen: Der erste Fall betrifft eine zweiunddreissigjährige Frau, die wiederholt normal 
entbunden hat, früler nie krauk gewesen ist, nur vor vicr Jahren vorübergehend Sehstörungen (Doppeltsehen) hatte. Nach ihrer letzten Entbindung vor achtzehn Honaten begann sie heftigen Koptschmirz zu emptinden, später zeigten sich Schwierigkeiten beim Kanen und Schlingen. die Stimme veriumlerte sich. Silhliesslich trat sie wegen Geschwürsbildung an Gaurnen in Behandlung. Es zeigten sich in der That an hinteren Fuile des harten Giamens eine grössere and mehrerc kleinero Ulcerationen, aluserlen besteht vollstïndige Atrophie der rechten Zungenhillfte, totale Lühmung des rechten Stimmbandes, Hypertrophie und Hypersecretion der Nasensehleimhant. Schwellung der Submaxillardrüsen, der Geruch ist vollig autgehoben, Geselimack ist vermindert auf der atrophischen Zungrenhälfte, dic auch schwache filmrillïre Zuchungen zeigt. Im Uebrigen ist insbesondere das Nervensystem in keiner Weise erkrankt, Pupillen- und Sihnemreflexe ganz normal. Nach Joikaligebrauch heilen die Geschwïre, Geruch mol Geschmack kehren wieder, aber die Atrophie und tie Stimmbandlähmung bluiben unvarindert. - In zweiten, weniger genau beobachtoten Falle handelt es sich um einen Schauspieler, der vor fïinf Jahren Syphilis acquirirt hatte. welcher seit einem halbon Jahre an Atrophie der linken Zungenhailte und linksscitiger Posticuslähmung im Kehlkopfe leidet: auch hier sinil alle sonstigen ncrvösen Eunctionen, insbesondere dic Reflexe völlig unversehrt. Verf. schliesst hieran eine sehr eingehende Besprechung der halhseitigen Zungenatrophie. Bemerkenswerth ist das nahezu constante Vorkommen dieser Atrophie zugleich mit gleichseitiger Kehlkopfinuskellïhmung. Verf. betunt vor Allen, dass diese Eikrankung durchans nicht immer Theilerscheinung der Tabes zu sein braucht, sondern wie in den mitgetheilten Fälen ohne jegliches tahetisches Symptom auf syphilitischer Grundlage auftreten kann. Die Erkrankung beruht aller Wahrscheinlichkeit narb auf Degeneration der bulbösen Ǩerne, hervorgerufen lurel syphilitische Erkrankung des entsprechenden Zweiges der Art. vertebralis.

kiaser.

Buek (11) berichtet über einen etwas dunklen Fall ron plützlicher and fast völliger Taubheit beider Ohren bei einem siebenjührigen Kinde, ontstanden in Anschlusse an einen Crompanfall. Er hielt anfangs die Affcetion für einen Nittelohrkatirrh mit consecutiver Labyrinthaffection, weil ansser Schwellung der inneren Trommelfellschleimhant nichts ubjectiv zu finden war. Bald aber erschienen symmetrisch an der hinteren oberen Wand der beiden äusseren Gehörgïnge unmittelbar an T'rommelfell eircumscripte geröthete Flecken (Periostitis), die er als auf tubereulöser Basis berthend ansah und durch Trepanation und 'Tamponide des Mastoïdfortsatzes behanitelte, doch ohne Erfolg. Später machte ihm die niachtrïglich bekannt gewordene Syphilis der Eltern diese Diagnose wahrscheinlicher, sicher aber keineswegs, da sich einigermassen sichere Kennzeichen diescr Kratukheit an dem kínde nicht fanden, auch koine Zahndifformitäten (nur eine Keratitis zweifulhafter Art kau später). Unter dauerndem internen Jodkaliumgebrauche trat nach einigen Wochen Besserung. spiiter völlige Wiedorherstellung des Förvermögens ein. $\mathrm{Buck}$ bezeichnet diese fragliche hereclitäre syphilis als tardiv; div er aber selbst angibt, dass er nur sehr ungenügend über das Vorleben seines kleinen P'itienten unterrichtet ist, so hat or dazu sicherlich kein Fecht.

Block.

Gradenigo (12) hat das Gehörorgan eines fünfzchnjihrigen, an Plthlise verstorbunen tabstemmen Mälchens secirt, über lessen Vergangenheit niehts zu aruiren war. Er fand im Wesentliehen beilerseitige vullstänlige Zerstörung des häntigen Labyrintlis, Noubildnn⿺r ron Faser- mud Knochengewebe, besonters links, wo and eine eitrige chronische Mittelohrentziundung vorlamilen war. Verf. glaubt hauptsichlich weren Luversehrthuit

Vierteljahresschrift f. Dermatul. a. syph. 1888. 
der Meningen und der Nerven (Acusticus und Facialis) auf eine primäre Otitis interna schliessen zu dürfen, auch die links bestehende chronische Mittelohreiterung scheint ihm secundärer Natur zu sein. Diese prinäre Otitis habe sich extranterin auf Grund hereditiirer syphilis entwickelt. Verf. theilt noch mohrere (fünf) Beobachtungen mit, wo 's sich stiner Ansicht nach um primäre Otitis interna auf hereditiir-syphilitiseher Grundlage handelte. In drei derselben bestand zugleich Iritis unltr Koratitis interstitialis, welche er in Parallele zur Otitis interna stellt. Symptomatiseh hervorzuheben ist, dass die Krankheit vorwiegend das wcibliche Geschlecht im Alter von zehn bis zwanzig Jahen befällt. Es werilen immer buide Ohren zugleich oder kurz alcheintuder belallen. Das Gehörvirmägen wirl rasch sehr erheblich vermindert und geht hïutig in Laufe der Zeit in völlige Taubheit äber. Beachtunswerth sind ganz unmotivirte abor sehr beträchtliche Geliörsschwankinngen von cinem Tag zum andern. Jovale uni allgemeine Reactionserscheinmüen fehlen bei Erwabhenen. Kinder haben zuweilen dabei Finber, cuntinuidiches Satusen fehlt fast nie: Schwinlel ist nicht immer und selten intensiv vorhanden: zuerst wird dis Perceptionsfähigkeit für hohs, 'Tönt? rermimlert. Das Mittrlohe ist anfangs mumal, später kann es zu Trommelfell-Truibungen. auch zu Otorrhes kommen. Vert. glaubt die von manchen Seiten gemachte Amahme, die syphilitisthe 'Taubheit beruhe auf nervöser odler centraler Erkrankung entselieden zurückweisen zu müssen. Die Doppelseitigkeit des Leidens begründet ein solche Annahme ebensu wenig, wie die doppelseitige Keratitis. Vielnehr handle es sich eben um eine primäre Otitis interna, die als solche bisher stets nur bei Syphilis (hereditärer und erworbener) nachgewiesen sti. Der Lymphraum des inneren Ohres sei auch eine Prälilectionsstelle f'ür das syphilitische Virus. Die Therapie ist fist immer ohne jeden Erfolg. nur im Anfangsstadium bietet eine energische antisyphilitische Behandlung einige Aussicht auf Besserung.

K a y ser.

Theobald (13). Ein vierundzwanzigjähriger Mann mit hereditärer Syphilis ist auf dem einen Ohre vollständig taub, das andere Ohr zeigt einen merkwürdigen plötzlich eintretenden Wechsel von deutlicher Taubheit und nahezu normaler Hörfähigkeit. Jodkali blieb ohne Wirkung, wirksamer erwies sich Sublimat, combinirt nit Salmiak.

Kayser.

Holm (14) veröffentlicht zwei Fïlle von rein centraler Anusmie bei zwei im Spätstadium der Lues befindlichen, auch sonst cerebrale Symptome darbietenden Patienten; - die Sinnesläsionen wurden durch specitische Curen gebessert. J it d is sulln.

Massei (15) beubachtete zweimal in Gefolge von gummöser Verschwirnng dor Rachengebilke narbige Adhärenz des Velums nud der Arcus palato-pharyngei an dic hintere Richenwand; daraus resultirten sprachund Gehörstürungen. sowie Ruspirationsbeschwerden. Durchtrennuny der Anwachsungen mit dem 'l'hermokinter and graduelle lbilatation britehten vollständige Heilung herbei. Terartige Folgezustände der syphilis können, wie Massei hervorlebt, Inreh rechtzeitige Isolirunge lel Fiste des Gaumensegels von der hinteren Plinryuxwand verhindert werden.

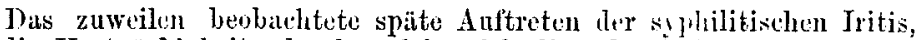
sowie die Hurtuitckigkeit, iurch welche sich liese luetische Minifestation auszeichnet, sucht Searenzio (16) aus der anatomischen lige und atus der Structur des Auges zu erklïren, welehe zwei Momente einerseits dem Eindringen des syphilitischen Virus bedeutende Hindernisse entgegensetzen und andererseits dessen Eliminirung, wenn es cimmal eingedrungen ist, wesentlich erschweren.

Durnig. 
Lucas (17). Patientin, eine Frau in mittleren Lebensalter, sieben Jahre verheiratet, ohne Kinder, welche über leftige Schmerzen spontan, besondurs aber aut brack, in der Trachea dieht unterhalb des Larynx. ferner über zeitweise aultretende Dyspnoc, etwas Husten und Auswurf klagte, hatte sich uf Jihre zuvor luetisth infieirt und ein nothen Ausschlag, Aufspringon und Schmerzlaftioncit dex Hïnde, Schmereen im Halse und Ansfiallen rer Hiare beobachtet. Nachdem sie damals behandelt worden, war sie bis zu ihrer jotzigen Frkrankung gesund geblieben. Bei der laryngeskopischen Lntersuchung fand $\mathrm{L}$ ueas einen goroitheten, fast das ganze Lnmen der 'Trachen dieht unterhalb des Kehlikopfes einnehmenden Tumor. Da er denselben für luetiseh hielt, so verordnete ar Jorkalium in Dosin ron 0.3 nul Lebertluran, ferner Inlalationen ron Kreoset mit Morphium genten die localen Beschwerilen. Als trotedem kcine Besserung eintrat, fing er auf Anrithen von Lr. Mc. Bride in Elinburg, wheher gleichfills den jetat in scinem Centrum verkisten l'uınor fiir cin Gumma lielt, grössere Dusen Jorkali zu guben an, unt stieg in Lanfe von zwei Monaten bis zn 1.25, dreinal tïglich, musste dann aber weren Kachexie der Patientin aussctzen. Lnter dieser Buhanilnng waren Sichmerzen und Tumor verschwunlen, so lass Dr. Me. Brille bei einer zweiten Untersuchung nur cine geringe Verengerung des Jumtens der Trachea in der Gegend der beiden ersten Ringe eonstatiren kunnte. - Unter den seltenen Fïllen von gummöscn Tumoren er 'l'rachea war dieser Fall wegen des gänzlichen Mangels anderer Erseheinungen der Syphilis besonders auffallend. Semon hat im St. Thomas-Fospital, Reports, Vol. XIII, auch einen Fall veröffentlicht, der, was den laryyogskopischen Pefund anlangt, mit de'n uben geschilderten grusse Achnlichkeit zeigt, sich jeduch durch das Vurhandensein tertiärer Erkrankungen des harten und weichen Gaumens unterscheidet. Da der oben beschriebene I'umor bis anf den Punkt gekummen war durchzubrechen, so würile, fills es zur Uleeration gekomnitn wäre, eine Narbe und dadurch unvermeidlich eine strictur dor Trachea entstanden seiu.

Curtin (18). Obwohl einige Aerzte die Secluft als sehr geeignet zur Behantlung her Phthise hinstellen, ist luch die Majoritat entschieden gecen eine solche Theripie, weil zwar für einige Wochen, vielleicht in Fulge der Luftverinderung, des Wechsels in der Ernihrung und Scenerie eino Bessertung, damn aber bei der goringen Wilerstandsfïhigheit gegen die dichte, feuchte, aufiegrende Salzinlt cinc un so bedentendere Verschlimmornm in tem Befinden der Patienten eintritt. Curtin beschreibt fünt Fäle von Lansensyphilis, in denen die Scelult sehr sianstion wirkte. Dass er es in diescu Fillen wirklich mit syphilitischer min nicht tuberrulöser Frkrankung der Lunge zu thun hatte, dafür sprachen dic sechs Symptome, welehe Porter für diese Erkrankung als charakteristisch hinstellt, nümlich: 1. Der massenhalte Auswart ohne irgend ein Zeichen von Einschmelang des Lungengewebes; 2. der Schwathezustand vhne besondere Abzehrung: 3. ansaesprochene Tyspnoe ohne irgend welches Hinderniss der Circulation von Seiten des Herzens oder der Lunge; 4. der eigenthümliche Schmerz und die Reaction bej Druck anf das Sternum und die Cristae tibiac: 8 . die schnelle Besserung bei antiluetischer Behandlung; 6. vor allen Dingen das Fehlen der 'luberkelbucillen. - Die Seeluft unterscheilet sich liufurch von der Höhcnluft, disss sie mehr Fenchitiglieit enthält, dass sie dichter ist, lass sie mit sillz gesthwängert ist. mil dass sie eine gringe Monge Jod enthält. Die dichtere, feuchte, salzhaltige A tmosphäre wîrde bei tubercalöser Erkrinkung der Lnnge wahrscheinlieh die Circulation des Blntes in dicser und den Zerstörungsprocess beschlemigen, während hingegen bei der Lungensyphilis die beschleunigte Blutcirculation 
einen günstigen Einfluss ausübt, indem sie die Ernährung der Lunge bessert. Die constante Inhalation geringer Mengen Jod wird wohl ebenfialls auf die Krankheit günstig einwirkın.

Zeising.

Fraenkel (19) find bei der Suction einer einundvierzigjährigen Frau in unteren Abschnitt ler Trachea eine Anzahl von theilweise ulcerirten Gummaknoten, in den Bronchien eine Anzahl strahliger Narben, ebensolche waren neben iden Knoten auch in der Trachea vorhanden. Beide Bronchien warch von infiltrirten, starrem bindegewebe umgeben, ant meisten der linke, welcher fest an den Aortenbogen alhärirt, und in diese Adhïsionen ist der linke Nervus recurrens einbezonen, der plattgerlrüelt und grau erscheint (während des Lebens bestand vollständige Lähmung des linken Stimmbandes). Dio Bindegewebsinfiltration erstreckt sich, winn auch in etwas creringerem Grate, bis enm nuteren Drittel der Trachea hinauf. Ausserdem fant sich ein gunhmöses Infiltrat in der Schildluüse, Gummatil der Leber und ciner Niere, Deforte und Auflasermnen an den Sehibdelknochen. - Die diffuse indurative Peritracheitis umil T'eribronchitis, dio allerdings kein constanter Begleiter der gummösen 'Trahtealsylhilis ist, ist wichtig als nenes ätiologisehes Noment der peripherishou Rourenslähnungen. Fraenkel hebt ferner hervor, dass der Ausgang der Trachealsyphilis keineswegs immer Stricturbildung ist, sondern dass tntweler wie im obigen Falle die Induration des amgebenden Binlegewebes das gefïhrdende Moment abgibt, uder dass durch Uebergreifen ulcerirter Trachealgummata auf die Nachbarschalft (grosse Gefïsse, Oesophagus) oder durch die Entwickelung von Mediastinalibscessen der ungünstige Ausurang bedingt werde. - Verfasser macht schliesslich auf die Seltenheit syphilitischer Erkrankungen der Thyreoilea, besonders bei alcquirirter syphilis, aufmerksam, und ganz besonders ist noch hervorzuheben, dass sich in obigem Falle in dem Gumma der Schild räse dio Lustgarten'schen Bacillen finden. Less er.

Sokoluwsky (20). Erst in len lutzten Jahren wurde diestm Gegenstande vom klinischen Standpunkte nehr Aufinerksamkeit geschenkt. und zwar gebührt in dieser Bezichung das Hauptverdienst Gierhardt (Deatsch. Arch. f. klin. Med. 1877), wonteh die Beobichtungen von Riege l, Vierling (der sechsundvierzig derartige Fïlle zusimmenstellte), berger und Auderen folgten. Dass Leiden tritt hauptsächlich bei Männern im Spätstadiun der Syphilis auf, in Folge von ulcerösen sich hier abspielenden Prucessen. In der Mebrzahl der Fülle ist dabei der Larynx auch in Mitleidenschaft gezogen, selten leilen die Bronchien daran allein. In Verlaufe der Krankhoit worden drei l'erivilen unterschiedten: das Reizungs(Uleeration), Verengerungs- und Suffocationsstadium. Das erste ist wenig. die beiden anderen durch das Auftruten von bestïndiger Athemnoth recht charakteristiseh. In (iegensatzo zu ähnlichen im larrynx loualisirten Processen wird eine Verminderung der respiratorischen Bewegungen der letzteren betont. Dur Ausgangr ist meist ein ungünstigor: die Patienten ersticken gewöhnlich in Folge von Verlegung der Bronchien mit eingedickten Schleimpfröpten oder gehen zu Grunde an profusen Bronchialbintungen, durch Arrosion grösserer arterieller Aeste. In Anschlnsse beschroibt Verf. zwei recht interessante, letal verlanfene Fälle, an denen beiden wegen Athemnoth die T'racheotomie ausgeführt wurde, und die alle beide nit ciner Lähmung des Mruse. crico-arytenoidei postici complicirt waren. Als Ursache dieser letzteren wird der Drutk seitens hypertruphirter und krankhaft verïnderter Lymphlrüsen auf den Nervus recurrens angegreben, was in einem Falle auch durch dic Section bestätigt wurde.

Heller (21) unterscheilet drei Arten congenitaler Lungensyphilis: 1. die gummöse Furm, 2. die weisse Pneumonie nath Virchow, 3. die 
interstitielle syphilitische Pneumnnir. Beide letztere Formen kommen nebencinaniler vor. Wuiss: Pnoumonio fand Verf. nur bei todtegborenen oder bei solchen Kindern. welche kurz nach der Geburt starben. Finder, welche minilestens stundenlang lekten, zeigten nur lit: interstitielle Form. Die weisse Pneunonie ist shly salten. Die Lungen sinel gross, weiss, grauwciss wher röthlich mamoritt. Sie lassen ohne Gewalt sich nicht aufblasen. l'lenra, Pericard, 'Jhymus kännen ecchymosirt sein. Die erweiterten Alreolen sind mit hescrimirten theils verfetteten. theils zerfallenen Epithelien üherfüllt. Die Kinder sind nicht lebensfïlig. Die interstitielle Pneumonie ist vorwingend um Bronchien und Gefisse localisint - bald herdfïmig. bald diffis. Die Iongen sind gross, derb, lufthaltig, dunkel oder hass. Das interalvoolare Gewebe ist verbreitert, überans reich an Bindenewobsasem, Rundzellen und Capillaren. Die Alreolen sind eng. die Fpithelien gerubllen pigmentirt. Das interlobuläre Gewebe ist rundzellenarm, lreit, fibris. Das rechte Horz kann hypertrophiren. Das ganze Bild erinnert an die ron Virchow beschriobenen indurirten unil pigmentirten Tungen von erwachsenen Mälchen. Virchow nahm in allen diesen Fïllen Syphilis congenita an. Dic Pneumonie beginnt zumeist fötal: sie kann ror der Geburt schon sehr ausgobillet sein. Iängeres Leben ist dann ausgeschlossen. Den Erstickungstod weisen Eechymusen in Pleura, Perieard und Thymus nach. Geringere Processe lassen fortleben bis über die Pubertätszẹt zu. Dic interstitiellen Prucesse können mit dem Lungenwachsthum selbst zunehmen. Vielleicht bezichen sich als Spätstadien manche Fïlle ron Iungenschrumpfung hierauf. Todesursache sind meist Bronchitis, Pleuritis, Alveolar-Pneumonie, Magen- und Darmkatarih. Atrophisch sind keineswegs alle derartigen Kinder. Eine gleichzeitige Tuberenlose sah Heller nie. Genaue Kenntniss der weissen und interstitiellen Pneumonie ist für den Gerichtsarzt unerlässlich.

Friedheim.

7icgler erwähnt eine Form von syphilitischer. Pneumonie des Nengeborenen, charakterisirt durch eine fettige Entartung des LungenEjithels und durch iiberall hinlaufende Infiltritionszüge. Forster spricht sich über dic Verbreiterung des interstitiollen Gewebes schr reservirt aus, da er solche auch unter vielen anderen Umständen fand. Cornil unterscheilet eine trockene opake rundzellenreiche und eine feuchte Epithelialzellenreiche Hepatisation bei Tungensyphilis. Depaul leugnet das Lungengumma der Nengeborenen. Ziegler gliubt im Gegentheil es viel hiufiger sogar bei solchen letzteren als bei Erwachsenen gefunden zu haben. Fournier findet in frühen Stadien eine grosse Aehnlichkeit mit Lungeninfarct oder mit metastatischen Iungenabscessen. Lancereaux nimmt zwei Formen von Pneumonia syphilitica an: 1. eine diffuse, 2. eine umschriebene. Letztere ist seltener; sie entspricht dem Gumma syphiliticum. Auch hier kommt es zu Nekrose, fettiger Degeneration der Elemente. Es kann Resorption eintreten, hiufiger wird das gummüse Gewebe ausgehustet. Dann bleibt eine Caverne zurück. Die Caverne kann narbig ausheilen. Carlier unterscheidet: 1. eine hyperplastische sklerotische (cf. diffuse nach L ancereaux), 2. eine gummöse Form. Ranvier und Cornil heben für die Pneumonia albi die Abwesenheit von Pigment hervor. Die interalveolïren Zellen sinl rundlich und jung; die Alveolen verkleinert, aber durchgingig, und mit Pflasterepithelien ansgekleidet. Die freien Epithelzellen sind granulirt und verfettet. An der Lungenoberfliche sieht man zuweilen Gummata, d. h. kleine harte rereinzelte oder gruppenartig angeorincte Tumoren ron der Grösse einer Linse bis zu der einer Wallnuss, ron rïthlicher oder grauer Farbe mit feinen weisslich-gelblichen Punktirungen. In einer zweiten Reihe ron Fillen beobachtete Lancereaux 
wallnussgrosse typische Gummata, theils mit Narbenhilung. theils mit centralem Zerfall, mit reichlichem Granulationscrewebe u. s. f. Cornil hebt für manche Fialle die Uebereinstimmung mit den gummösen Bildungen beim Erwachsenen hervor. Nach Fournier ist charakteristisch für das Gumma: 1. das vereinzelte Vorkommen ohne Priddilection tür die Spitz $\bullet$ n, 2. die gelblich-weisse, nie durchscheincnde Farbe. 3. eine genisse, stlbst im Stadium des Zerfalls, porsistirende Härte des frewebss - gragenüber dem Tuberkel. Hierzu komme nach $B$ a nmgarten 4. die Abwesenheit der 'I'uberkelbacillen, das Ferhalten der Gefiisse. Irie anatomische Inillerentialdiagnose ist nach Devic für gewisse Fülle gerall.zu ummöglich. Und für die klinische ist das sicher beobachtete nicht zu soltene geparte Furkommen von Syphilis und Tuberculosis pulmonum nicht zum mindesten Theile verhängnisswoll. Devic (22) hebt nun klinjsch 1. diejenigen Falle hervor, bei denen alle Respirationsstïrungen fehlten. Die jüngeren sklerosirten Partien sind nach Fon rn ie rorgualbt, die alteren sind eingesunken. Da nun aber die griue Induration iler Lunge nicht sulten. bei alten Ienten ïberhaupt, speciell ferner bei Alkoholikern, bei heralgekonmenen Individuen, bei solchen, die an Albuminnrie litten. beobachtet worden ist, da anderseits fibrüse Zügc, Narbengewebe, Cavernen nach abgelaufener und bei progressiver Tuberculose geradezn typisch sind. so chlaubt Devic nach Tripier, mit der Diagnose Syphilis nach derartigen Befunien nicht rorsichtig genug sein zu könncn. Die Diagnose wird noch unsicherer durch die verschiedenartigen interstitiellen nieht syphilitischen Pnemonien. Bronchiectasien u. s. f. Fünf Fälle von Lungengumma führt I) evic an; und er erwähnt das Vorkommen der Riesenzellen besonders bei denen, wo der Nachweis von Gumma pulmonis ein zufïlliger war (cf. Cholera-Epidemie 1863 nach Ranvier), 2. diejenigen von tertibirer Syphilis mit Ruspirationsstörungen. Das wichtigste Symptom ist die Dyspnoe - aurickzuführen nach Rollet 1. auf Verkleinerung der Oberflïhe, 2. Retraction der Bronehien, 3. complicirende Katarrhe, 4. alveolire Infiltration. Die Drspnoe kann sich bis zur Orthopnoe steigern. Der Husten ist anfangs trocken, am stärksten Nachts. Der Auswurf ist schleimig, eitrig nur li.i Vlcerationen in der Trachea, bei Cavernenbildung. In Auswurf sind gummüse Fetzen nach $\mathrm{Ca}$ be charakteristisch. Hämoptysen sind seltun. In den rorgeschritteneren Stadien sind die Franken sehr kachektisch. Belin nnterscheidet 1. eine leichte hlinische Form mit den Zeichen der Bronchitis, 2. eine mittelschwere mit abgeschwächtem Vesiculärathmen, aber nmschriebener Iocalisation, hin und wieder mit Cavernensymptumen bereits, 3 . die schwere Form mit Fieber und Nachtschweiss. Die Lungenveränderungen gehören der Tertiörperiode an. Hin and wieder hat Fournier in der secundïren Periode Dyspnoe beobnchtet - ohne nachweisliche Processe in der Lunge selbst. Fournier hat Lungensyphilis bei Ines hereditaria tarda beobachtet. Die Fälle von Iungengumma sind sehr selten und stets ron tertiären Processen in anderen brginen begleitet. Jerlenfalls trift' Lungensyphilis ebensowohl Erwachsene wie Neugeborene - beide aber sehr stelten. Die sogenannten therapeutischen Erfolge berichen sich gewiss zum grössten Theil auf reparable tuberculäse Veriinderungen syphilitisther Personen.

Friedheim.

Schuchter (פ3) hat zweiundzwanaig Kranke. die theils ,mit der syphilitischen Initialsklerose beluattet waren, theils an then frischen Formen constitutioneller syphilis" litten, in IFinblick aut Virühlerungen der Milz einer genauen hlinischen Beobachtung unterzogen. In sedw Fiallen war jede andere Ursache eines Milztumors ansgeschlossen. In dra Fillen aus letztgenannter Zahl war ein maculöses oder papulöses Exanthem ausgebildet. In einem Falle war es müglich, das Wachsthum des Tumors zu beobachten. 
Zu Grunde legte Schuchter ein Normalmass ron $\mathbf{5}-\mathbf{5}^{1}$ Ctm. für den Breitendurchmosser des Organs. Dieses Mass wurle bis um 3 Ctm. (im Ganzen $=7 \%-8 \mathrm{ctm}$.) überschritten. Nach vorn überrate der Tumor die Linea costoclavicularis. In zwo Fällen schwand der 'T'umor auf antiluetische Bohandlung hin. In einem Falle war letztere anf den Tumor ohne Einfluss geblieben. In weiteren drei Fällen von frischer Syphilis waren die Kranken gleichzeitio stark animisch. Durch antiluetische 'I'heripio wmiten Milztumor und Anämie beseitiort. Verf. schliesst anf einen ätiologischen Zusammenhang zwischen Milztumor und Anämie. In Betreff der Nierenaffectiınen schliessen sich die Angaben Schuchter's an diejenicren von Doscourt, Perroud. Iancereaux und Wagner an. Von den Kranken mit Anschwellung der Milz wurlen siebzehn auf Albuminurie geprüt. An zwei Kranken geling es eine Nierenaffection nachzaweisen. In cinem Falle hielt die Albuminurie dreizehn 'Tage an - im Sediment fonden sich Plattenepithelien - im zweiten Falle nahezu sioben Wochen. Hier war eine gewisse Entpfindlichkeit in der Nierengogend zu bemerken. zeitw ise abendliche Temperntursteigerungen (bis zu $384^{\circ}$ ), Vermehrung des specifisehen Gewichts, betrichtlicher Gehalt an Albumen. Im Sediment sah man theils platte theils geschwïnzte Epithelzellen, hyaline und granulirte Cylinder. Die Harnmenge blicb annühernd normal. Auch in diesen Fiallen war die antiluetische Cur nach der speciellen Richtung hin erfolgreich.

Friedheim.

Tommasoli (24) beobachtete bei einem neunmonatlichen, hereditär sjphilitischen Kinde die Entwicklung eines cnormen Milztumors, welcher fast die ganze linke Hälfte der Banchhöhle einnahm. - Tommasoli ist geneigt anzunehmen, dass die in Verlaufe der Lues auftretenden krankhaften Veründerungen der Milz, der Leber und der Nieren auf die toxische Wirkung des Syphilisfermentes (?) nuf das Blut and mittelst des Blutes auf die Baucheingeweide zurückzuführen seien; er stellt somit die viscerale Syphilis in eine Tinie mit den Erkrankungen der grossen Bauchdrüsen, die bei gewissen Vergiftungen, z. B. mit Alkohol, Phosphor u. s. w. beobachtet werden.

Dornig.

Die Diagnose einer syphilitischen Holenerkrankung wird nach Mauriac (20) hauptsichlich durch drei Factoren gesichert. Erstens finden sich inmer mehr oder weniger ansgeprïgte luetische Allgeneinerscheinungen. dann ist der Nebenhoden, der bei den meisten Frkrankungen des Hodens stark in Mitleidenschaft gezogen ist, bei einer syphilitischen Orchitis meist frei und schliesslich gibt, wie bei jeder Erkrankung auf syphilitischer Grundlage, der Erfolg der antiluetischen Thernpie den Ausschlag. Der Verfasser unterscheilet zwei Folmen: eine sklero-summüse und eine gummosklerïse. Bei ersterer Form schwillt der Hoden bis zu Hühnereigrösse, ist gleichmisssig hart, wie von Holz, mit glatter Oberflaiche oder geringen Erhabenheiten. Die moist beiderseitig anftretende Anschwellung ist nicht schmerzhaft. Differentiell diagnostisch kommon das Iymphadenom des Hodens, sowie das Carcinom in Betracht, die indessen wegen - des meist einseitigen Sitzes, sowie wegen des Fehlens anderer luetischer Frscheinungen ziemlich leicht aus\%uschliessen sind. Bei der zweiten Form, in der die Syphilis den Hoden befïlt, der gummo-sklurisen, entwickelt sich aus einer Beule an der vorderen Seite des Hollens ein kraterförmiges Gesehwür, welches serise Flïssigkeit und "nassem Flichs oder Stockfischfleisch" ähnliche Massen entleert. Hierdurch und durch das alleinige Bufillensein des Hodens unterscheidet sich diese Form ron der T'uberculose des Hodens, die fast immer Nebenhoden. Samenwege und Prostata in Mitleidenschaft zieht. Von schweren Folgen für den Gesammtorganismus ist die Syphilis 
des Hodens gowöhnlich nicht beglitot. Was dio Zengung wihigkeit betrifft, so ist dieselbe solten alterirt und dann weniger wegen Cntergauges dos Hodemparenchyms, welches wohl nie tanz zerstort wirl, als wogen eines

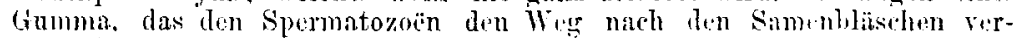
legt. Doch ist auch in einer Anzahl von Fillen derartigrr Azoospermic durch eine antisyphilitische $C u$ die geschlechtliche Function vollstiandig wielerhergestellt worden.

Jacobi.

Im Anschluss an die kurz zuvor crschionen: Arbcit ron Iaffitte

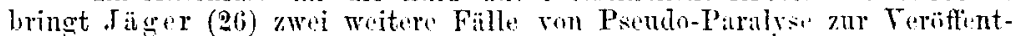

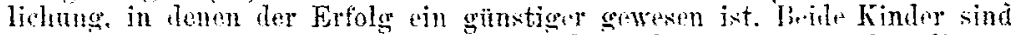

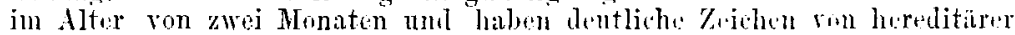
Idues: in ersten Ealle ist num der ruchte, im zweiten bedir Arme ron Pseulo-Paralyse betallen.

Töplit\%.

Gazin und Iscovesco (27) erörtern in einer sehr ausführlichen. mit einer sehr gründlichen Konntniss der framzïsischen. engliseluen and deutschen literatur geshriebenen Arbeit die Bozithungen zwishen Syphilis und Rachitis. Nach eintel historisehten Finleitung lesprechen sie zun̈̈chst dic Anatomie der Knochenverinderungen bej hereditiorer Sybilis und untersclueiden hierbei nach dena Vorgange We Grade oder Stadien: 1. Bei Föten und im ersten Findesalter sind ilic Knowen dünner, das Periost ungleichmansigr alhürent, auf der Obertlïthe der Knochen finden sich Osteoplyten, deren bisher bekannte histologische Structur nichts Charakteristisches hat, deren multiples Auftreten aber besonders an den Rürenknochen, an der Scapula und am Kopf fist pathognostisch ist; das symmetriscle duftreton derselben, ant welches $\mathrm{P}$ arrot grosses Gewicht gelegt hat, konnten die Verfissele nicht constatiren: im Innern des Knochens ist die Verknöcherungszone hïhor, weicher, durchscheinender und unregelmässiger als in der Norm: das spongiöse Giewebe hat ein granitartiges" A ussehen. 2. Das zweite Stalium (oder die zwite "Varietiit"), das meist mit zwei Monaten beginnt, ist ausgezeichnet dureh .die gelatiniforme Atrophie" Parrot's, deren histologische Deutung bei den verschiedenen Autoren noch eine verschiedene ist. bei welcher aber auch nach der Anschauung der Autoren das entzündliche Flement, die Granulationsbildung das Primäre billet; sic loealisirt sich vorwiegend in der Nïhe der Epiphysen, die Knochen werden weicher, wenn anch die , Ostenphyten ${ }^{4}$ noch fortbestehen; die Epiphysen verbreitern sich: hiufig kommt es zum spontanen Epiphysenbruch. Anch hier ist nicht das histologische Bild - das z. B. bei Tuberculose ein ganz z̈hnliches scin kïnne - das charikteristische, sondern die Iocalisation, vor Allem das multiple Auftruten ("Pseuloparalyse" Parrot's bei multiplem Epiphysenbruch); dic Craniotabes wirl in Uebereinstimmung mit den deutschen Autoren (in (ivgensat: besoniers zin den Engländern) als im Allgemeinen nicht luetischer Natur angesehen. 3. Das dritte Stalimm beginnt itwa nach sechs Monaten. Die Osteophyten werdon poriser. Reichliche Vascularisation, Proliferation von Mirk, Entkalkung, Bililung von Lückin mit reichlichèn Narkzollen in dem Knochengowebe findet sich im Knochen: neuer Knochen lagert sich auf der Oberfläche ler Osteophyten ab; endlich bildet sich "spunguides Gewebe", aut welches die Verfasser ein besonderes Fewioht Legen. Dasselbe erschuint zuerst weich, gefüssreich, einem feinen schwimme ihnlich; dann verkalkt es uni neigt zn einer fibrösen Transformation des Markes. Bei dem Vergleich der syphilitischen und der rachitischen Vurinderungen der Innochen (auch auf die letzteren gehen die Verfasser näher ein) zeigt sich zunïchst, dass zwischen den beiden ersten Stadien der congenitalen Knochenlues unil zwischen Rachitis keinerlei Analogie 
besteht. Im dritten Stadium kïme nur das bei beiden Krankheiten rorhandene spongoide Gewclye in Frage, das freilich an Iuetischen Finochen viel härter ist, als an rnchitischen; aber dieses Gewcbe ist für keine ron beiden Affectionen charakteristisch; die Verfasser haben es auch in mehreren tuberculösen Fnochen gefunden - es ist also überhaupt nichts Pathognomonisches. Der anatomische 'Theil der vorliegenden Arbeit schliesst mit dem Satzo: "Diu syphilitischen Knochen zejgen niemals spongoides Gewebe mit den Eigenthümhehkeiten des sitzes etc. bei der Rachitis, auf der anderen Seite bieten die rachitischen Inuchen niemils Osterphyten dar mit den Charakteren des Sitzes etc. bei cher Syphilis: es gibt also keine Beriuhungen zwischen der frühzeitigen congenitalen knohensyphilis und zwischen ier Rachitis." In dem zweiten - klinischen - Theile wird zunïchst der Werth der äusseren Zeichen für überstandene congenitale lues besprochen and in einer sehr ansführlichen und durchans berechtigten Weise gegen den Standpunkt Parrot's pulemisirt, welcher alle möglichen Hatutnirben, dio verschiedensten Verïnderungen der Zähne (nicht blos die typischen Hutchinson'schen), die "erâne natiforme“ in jedem Falle für pathognomonische Zichen der Ines ansicht und auf ditse Weise zu colossalen Zahlen gelingt - eine Pol'mik, die in Dentschland nicht einschender referirt zin werden brancht. Es wird dam aus dem in der franzïsischen, englischen und deutschen Literatur zusammengostellten Material. und aus eigenen Beobachtungen an 107 rachitischen Kindern, deren Einzelheiten nichts Besonderes darbicten, der Schluss gozogen, dass - wio ja selbstverständlich - syphilitische Kinder auch rachitisch merden können, dass sich aber unter rachitischen Individuen solche mit sicheren Zeichen vorangegangener Lues nicht häufiger finden, als unter der gleichen Anzahl nicht rachitischer. Dass Syphilis zugleich mit Rachitis rorkommen, dass sie sogar eventuell pridisponirend für die letztere wirken könne, leugnen die Verfasser nicht; wie wenig aber ein enusaler //usammenhang zwisehen beiden Affectionen besteht, beweisen sie dureh einige Fülle, in denen Eltern, die zunächst rachitische Kinder erzeugten, sich nachtrïglich inficirtun und dann sogar nichtrachitische Kinder hatten; sie citiren endlich noch lievbachtungen, welche zeigen, diss sich rachitische Inıliviluen syphilitisch inficiren können - wis jedenfalls in Analogie mit der Soltenheit der Reinfection - dann ausserordentlich selten sein müsste, wenn die Rachitis wirklich eine luetische Affection wire. Am Schlusse ihrer Arbeit betonen Cazin und Iscoresco, dass es allerdings cine ,syphilitische Pseudo-Ratchitis" gebe, die sich aber von der eigentlichen Rachitis unterscheile: durch die Inconstinz und Soltenheit der Epiphysenverdickungen, durch die Asymmotrie der Knochenverinderungen überhanpt, durch die winkeligen Knickungen der Röhrenknochen - im Gegensatz zu den eurvenartig gebogenen Glitelern Rachitischer, durch die multiplen Osteophytenbililungen etc. Dieses Krankheitsbill wird noch durch einen Fall illustrirt. Jallassolin.

Suckling (28) demonstrirt in der pathologisch-klinischen Section zu Birmingham (28. I. 1887) cin Kind mit Epiphysitis syphilitica. Dasselbe ist fïnf Wochen alt. Die unteren Enden beillr Radien sind hochgradig angeschwollen. Gleiche Schwellungen sind auch an den unteren Extremitäten beobachtet. Das Kind schreit bei der leisesten Berührung; es ist untïhig, die Glieder zon bewogen.

Friedheim.

Eschle (29) berichtet über rior Fïlle luetischer Knochenerkranknngen der Finger, in denen sich an zwei Individuen der Process al:s Osteomyelitis (Kinder), an den beiden andern als Periostitis mit secundärer rareficirender Ostitis und Nekrose (Erwachsene) maniféstirte. Verfasser 
glaubt im Gegensatz zu Lewin welcher in seiner sorgfultigen Statistik (Char. Annal., Berlin 1879) die schon früher von Chassaignac, Taylnr, Riset etc. publicirten Fille sichtete und in der Nomenclatur eine Plialangitis syphilitica im Gegensatz zn Frkrankungen dor Trichtheile differenzart.wissen will - ans einem Falle der Ansicht B ïumler's beitreten zu müssen, dass die Phalangitis auk secundär von Erkrankungen der Weichtheile herrühren kijnne. In ter 'That wird nach Analogie anilerer patholorischer Processe die Eventualitït nicht golengnet werden kïnnen. Bestätigrt wird durch vorliegende Krankengeschichten der Satz Lewin's, dass bei Kindern melnr die ostcomyelitiche, bei Erwachsenen mehr die periustale Form rler Dactylitis syph, in die Erscheinung tritt. Eigenthümlich erscheint, dass in zwei Fïllen (Motter und Kind) Fxarticulation der betreffenden cilieler nöthig wurde. dia antiluetische Therapie vällig erfolglos war, auch war bei der Mutter Hämoptor nul bei dem Kinde Liimpfung einer Itungenspitze zu constatiren. Auf 'T'uberkelbacillen wurken die Prïparate nicht untersucht, deren eines ein Rundzellengewebe mit spürlich eingelagerten gofaserten Knochenlamellen erkennen hiess. Die zallluichen Blutgefüsse zeigten verdickte Intima und Adventitia.

L, 0 wenh ir $\mathrm{r}$ t.

Sakotski (30) berichtet ron einem jungen Soldaten. mit Ulcerationen des Gaumens und consecutiver Zerstörung der unteren Muscheln. Es bildete sich ein Tumor über dem Auge; der Patient bekam Sehmerzen im Knie- und Fussgelenk, eitrigen Ausfluss aus dem linken ohr und einen metastatischen Abscess auf dem Rücken der rechten Hand. Zwei Jahre glanbte man, dass es sich um syphilis handele. Es bildeten sich jetzt Knoten im Gesicht; dasselbe wurde odomatös. Man vermuthete Rotz. Der Kranke starb an algemeinem Marasmus. Vigandt untersuchte Knötchen und Gesehwürseiter mikroskopisch: er fand Bacterien, die er mit denjenigen von Löffler und Schütz identificirte.

Friedheim.

\section{Hereditäre Syphilis.}

1. Abner Post. Cases illustrating the late manifestations of enngenital syphilis. - Boston med. and surg. journ. 1887, $\mathrm{Nr}$. 91.

2. Haratonx.J. De quelques alterations de l'oreille interne dans la Syphilis héreditaire. - Le Progrès médic. 1887, Nr. 4.t.

3. Krans Ed. Statistische Beiträge zur Pathologie der Lues congenita. - Arch. f. Kinderheilkunde, Bil. IX. Heft 2. pag. $81 \mathrm{ff}$.

4. Moncorvo. Die Aetiologie der multiplen Herdsklerose im Kindesalter und insbesonderc über den pathongenen Eintluss der hereditären Syphilis. - Revue mensuelle des malalies de l'enfiants, Juin 1887, pag. 2.4 ff.

5. White Hale. Congenitale Syphilis mit amyloider Entartung der Viscera. - Lancet-Clinic 1887, Nr. 3351, pag. 1013.

6. Pedicini M. Nuove ricerche sulla sifilide placentare. - Progresso med. 1887, pag. $2-18$.

Abner (1). Bei den hereditär syphilitischen Kindern verschwinden die Jrankheitspacheinungen gewïhnlich noch vor Ende des zwojten Lebensjahres, um bei den einen nie, loi anleren erst in der Pubertät oder noch spaiter wieder andzutreten; bu einer laitten Gruppe affenbart sich die Erkrankung in mehr mler weniger häufigen, in unregehmäsigen Zwischenrïumen sich zeigenden Eruptionen. Die zwei crsten Jahre umfassen die Frühformen der syphilis hereditaria; die später auftretenden Furmen kann nuan als Syph. her. tarda bezcichnen. Die Diagnose deiselben kann gestellt 
werden aus Zeichen früherer Erkrankungen, aus dem Zurückbleiben im Wachsthum und aus den gegenwïrtig vorhandenen Symptomen. Es kommen jedoch, ebenso wio bei der acquirirten Syphilis, Spätformen der Erkrankung vor, ohne dass sich frühere Erscheinungen derselben erviren lassen. Die Spätformen der Syphilis hereditaria tarda sind seler mannigfaltig und bereiten zuwcilen dieselben Schwierigkeiten in der Diagnose, wie die der acquirirten. A bner führt nun cinige Fïllo an, um die Figenthümlichkeiten des Spätstadiums der Krankheit und den Finfluss dor Behandlung zu illustriren. Fall I. Achtjïhriges Mïrchen. Vater vor Geburt desselben lnetisch. Pationtin in der Fntwickelung zurückgeblieben. Perinstitiden an verschiedenen Knochen, in Folge derselhen entstandene ulcerisc Processe, welche zur Ausstossung von Kinochentheilen führten. nicht whärente and adhïrente Narben, ron denen dic ïlteste anf dem Handrickin befindliche von einer im eilften Monate rorhanden gewesenen Frkrankung herrühren soll. Radiür rerlatuende, foine Narben an den Mundwinkeln. In Folge antiluetischer behandlung hoilon die Geschwäre, die Prinstitiden rerschwinden. Nach Aufhören der Behandlung Auftreten einer Nekrose dos Oberkiefers, ron dem ein Theil mit den Zïlnnen entfernt werden muss. Wiederafnahme der Behandlung mit Jod und Quecksilber. unter welcher Fissuren an der Nase, rhematische Schmerzen, ein leichter Vaginalkatarrh, klcine Periostitiden, welche inzwischen aufgetreten waren, sehr bald verschwinden. die durch Entfernung ron Theilen des Oberkiefers gesetzte Wunde verheilte und das Mädehen entwickelte sich kräftig. Dieser Fall zeigt, dass es nur dann za Knochennekrnsen kam, wenn die Feriostitis nicht behandelt wardo. Fall II. Siebzehn Jihre altes Mïdchen. Vater an allgemeiner Paralyse gestorben. Seit dem vierten I Jebensjahre schnerzhaite Periostitiden an den verschiedensten Knochen, an beiden Tibiae Exulcerationen und Exfoliationen von Knochen. Pationtin in der Entwickelung zurückgeblieben. Therapie: Grosse Dosen Jod, kleine Mengen Quecksilber. Die Schmerzen verschwanden, die Geschwüre vernarbten, Patientín konnte wieder gehen. Sie weigert sich, Jnd weiter zn nehmen. Bald Periostitis und nachfolgende Destruction der Stirnknochen. Hereditäre Belastung in diesem Falle zwar nicht ganz sicher, trotzdem Diagnose bei der gleichen Erkrankung zahlreicher Knochen nicht zweifelhaft. Fall III. Zwölf' Jahre altes Müdchen. Mutter tuberculös. Geschwister gesund. Als kleines Kind luetisches Exanthem und rhenmatoide Schmerzen gehabt. im Alter ron zehn Jahren periostitische Schwellungen an den unteren Fnden beider Fumeri, ron denen eine aufgebrochen war und zu einer Fistel geführt hatte. Entwickelung die eines sechsjïlrigen Kindes. Tubera frontalia stark hervortretend. Kindliche Gesichtszüge. Nasenbeine platt. Trübungen der Cornene. Erkrankung eines Ohres. Verschiedene Abnormitäten der Zähne. Periostitis an den Humeri besteht noch. Nervöse Attaken. welche dreimal wïchentlich, stets bei Nacht anftraten und eine Stumde anhielten, bestehend in schwindelgotïh, dem Uebelkeit und Frbrechen folgte. Bewusstsein während der Anfiille erhilten. Verschwinden derselben mit Jodkali, ebenso Nachlassen der plïtzlichen Anfülle ron Tanbletit. welche bisweilen auftrater. Patientin entwickelt sich ron dil an gut. Fall IV. Patientin gesund bis zum achtzehnten Tahre. Plïtzlich Nachtis epileptischer Anfall mit Bewusstseinsverlist und Krimpiton im linkon Arm nnd Bein. Wiederholnng der Anfälle nach einiger Zeit. Zurückbloiben von Schmerzen im linken Arm und Bein und unregelmässigen krampfhatten Bewegungen der linken Hand. Zuckungen der Muskeln am linken Mund-und Nasenwinkel beim Herausstrecken der / hunge. Reflexe normal. Cutersuchung ergab zarte radiär verlitufende Narben an den Mundwinkeln. Zahlreiche Narben an den verschiedenen Kürpertheilen. Hutchinson'sche Zähne durch den Gebrauch 
abgenützt. Die unteren Zähne zeigten cinen Substanzrerlust wie bei cinem fünfzigjölhrigen Manne. l'atientin blieb nun cin halbes Jahr gesunil. Dinn Auftreten von Tumoren im Nacken, auf dem Kinf, an der Clavicula, an anderen Körpertheilen, besonders gross auf der stirn. welcher etwas schmerzhaft war. Urin jetat trübe. zeigte Sumen ron Eiwoiss mol hyaline und granulirte Cylinder. Viurndzwanzigstündige Nenge steigt im Jaute der Zeit von 13:00 anf 3810 Gtramm. specifisches Gewicht sank ron 1040 anf 1004\%. In Folge von behindlung rerkleinerten sich einige f'umoren, andere vereiterten. Zunïhst Besserung des Allgomeinbefindins; dann Versehlimmerung: Ulcerationen an den Beinen, Ferlust des Gehors, fortwährendes Kopfweh, Erbrechen. Exitus lethalis. Autopsie nicht gestattet. Die Narben an den Mundwinkeln, die alegentzten Hutchinson'schin Kïhne sprechen für hereditäre Ines. Gummösc Periustitis komunt dabri sceltuner ror, ebenso Epilepsie hitutiger bui acunirirter Ines. Der Zusammunhung der Nierenerkrankung mit Lues lässt sich bestreiten. Fall V. Kate C., zehn Jahre alt. Vater zingt Parese beider Ame. In der Familie ki.ini venerische Erkrankung. Tier ersten Finder im sitbenten und achten Monate: tolt geboren. Fünftes Find war Pationtin. Als Kind immer krinklich, be sonders an Verstopfung dir Nase leilend. Sechstes und siebentes Kind gesund. Das Nervenleiden des Vaters, die Reihe der Aborte, welche der Geburt des ersten lebenden Kiniles vuransgehen. bewcisen Lues zwar nicht, machen sie aber wahrscheinlich. Patientin zeigt Nekrose der Tibiac. 'T'riibnngen der Corneae. An den mittleren oberen Sclncidezilhnen an Stelle der Hutehinson'schen Einkerbung eine dunkel gefärbte Substanz. Duntin, nicht von Schmelz bedeckt. Der vurdere Theil des oberen Alveolartortsatzes fehlt, so dass beim Schliessen des Mundes zwischen den Schncidezïhnen der beiden Kiefer cine bedentende Lücke bleibt. Frysipel. Furunkel. Auch in diesem Falle ist dit Knochenerkrankung primär. die der Uleeration der Haut secundar. Fall VI. Mr. D. Syphilis beim Vater nicht sicher nachzuweisen. Mutter an Phthise gestorben. In Alter von zweieinhalb Jahren zeigte Patient Dactylitis des rechton und linken Mittelfingers nnd des linken Daumens. Auf den Armen weisse, unter dem Nireau dex Haut liegende unregelnässig runde Narben. Im Gesicht, Nacken, auf der rechten Wange, dem Rücken der linken Hant, auf den Armen, an den Unterschenkeln Ulecrationen, zum 'l'heil mit dicken, dunkelfarligen Krnsten bedeckt. Linkes Fussgelenk stark geschwollen, an der Immenfliichic gerithet, an der Aussenfläche mit dirken Krusten beteckt. Tibiae verbroiturt. Luberthran olne Erfolg angewenlet. Die Knochenlisionen an den Fingorn. die Ulecrationen, die Kirusten wh die Narben, der Misserfolg mit dem Leberthrin machen die Diagnose Syphilis wahrscheinlich. Innerlich Jolkali. Behandlung der Wunden mit Quecksilburptlaster. I angsame Bessirung sowohl der localen Erscheinumgen, wie de's Allgemeinbefindens. Nach füntmonatlicher Aussetzung dor liehandlung keine Versehlimmorung. Fall VII. Loealisation dor Erkrankung hauptsichlich in Halse. Haut und Finochen zur Zeit frei. S. J., zwölf Jahre alt. Vater an Phthise gestorben, Mutter wer Lates veriächtig. Iatient hatte. arei Monate alt, Schmufen: zwei Jahre alt, Halsschmer und Kurzathmigkuit; ein Jahr spiter Verhst der Stimme, zu heiten etwas Busurung. Statns: Entwickelung gut. T'ubera

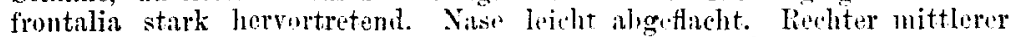

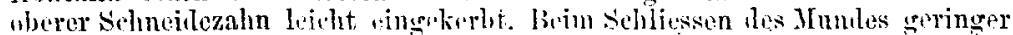

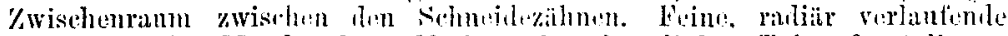
Narben an den Manilwinkeh. Niorben üher hun linken T'aber frontali, an den unteren Partien des Rumples mil am Steiss, wriss, mrogelmissig rund, $1 / 4-1 / 2$ Zoll im Dnrchnesser. Le ichte Trübungen der Corneite. Tiabheit auf dem rechten Ohre. Heistre, kilum rernchmbare Stimme. Beschleu- 
nigte Respiration, etwas Dyspnoc. Ausgodelente Narbenbildungen im Pharynx und Laryax, Schwellung und Ankylose beider Arrthatenidhnorpel. Verfasser schliesst aus diesein Fïllen Fulgendes: Wie Full $V$ zeigt, besitzen die Hutchinson'schen Ziilne nicht immer die typische Einkerbung, sondern die stelle, an der spaiter eine solche entsteht, ist ansgefüilt von einer uuvollkummenen und vertärbten Zallnmasse. Fall IV bewtist, dass in späteren Jahren llurch Abnützung der Zühne die Einkerbung vorschwindet. Fill $V$ und VI zeigen eine zucrst von Colman und $\mathrm{Hutel}$ inson erwähnte, sehr hänfig vorkommende Eigenthümlichkvit. nümli!h ein Zurückbleiben in der Entwicklung Res vorileren Alveulartheils des Oberkiefers. so dass beim Schliessen des Muntes zwischen den Schneidezïhnen eine lücke bleibt. - Kleine Kinder von einigen Wochen haben oft Erosionen an ihren Lippen. Turen Seeret gelhe Krusten bildet. Diese oburtlïchlichen Verïndernngen hinterlassen keine spuren. Nach lrei DFonaten aber tretin meist zu beiden Seiten der mittleren Hervorragutug der Objerlipe und in der Mitte der Unterlippe Fissuren auf, welche $1-2 \mathrm{Mm}$. tief sind. An den Humlwinkeln sind die substanzverlnste ausqedehntere. Die darans resul-

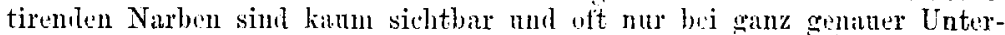
suchung za finlen. Die Narben an den Mandwinkeln siml besonders

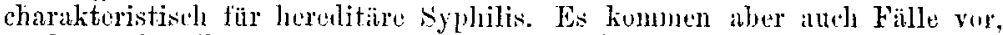
in denen dieselben ein. andere detiologie haben, dann fohlt aher stets die für Lues charakteristische lincare Foriı der Narben. Fär Frkrankungen

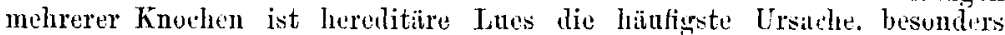
wenn symnetrische Knochen und hier wieder die älssersten Enden der langen Knochen ergriffen sind. Obgleich in Fall IV trutz der Behandlung der Patient wegen der Schwere der Erkrankung zu Grunde ging. so sind doch gewöhnlich die Erfolge ausgezeidhncte, uml zwar emptiehlt es sich; wie bei der tertiüren Lues, Jodprïparate, mul zwar in schweren Fiallen in grossen Dosen, zusammen mit Quechsilber anzuwencen. $Z$ e is ing.

Baratoux (2) berichtet über die anatomischen Befunde im Gehörorgan von 4:3 hereditïr-luetischen Kindern, von denen 19 tolt geboren waren, 2'. cinige Stumden bis vier Jihre gelebt hatten. Er fand g7 Mal Verïnderungen der Paukenhöhle, $4 \mathrm{Mal}$ solche des Labyrinths, 12 Mal solche an beiden Theilen. Waren Mittelohr unl Ialbyriuth affileirt, so hatte sich entweder dic Eiterung vom ersteren auf dis letztere furtogetat oder die Gebilale des Jabyrinths waren wenigstens injicirt, nit liundzellen infiltrirt und mit serüs-liämorrhagischer Flüssigkteit grefült. Besonders hervorzuheben aber sind die Beobachtungen. welche der Vertasser am Gohörorgane von Kintern miahte, bei tenen aussehliesslich das Labyrinth afficirt war. Hier fanden sich nämlich an den sehr reichlich entwickelten Gefïssen Verdickumer ihrer Wamlungen mit nuchlolgender obliteration mud zum 'Theil recht reichlichen Hämortharrien. welche den Cortischen Canal stellenwoise gauz ausfïllten. Es konmen also in Iabyrinth dieselben Verändernngen vor, wie sie auch in den inderen Organen hereditïr-lnetischer Kinder constatịt worden sind. Jatissuhn.

In einer statistischen Uebersicht aus der poliklinischen Abtheilung les Prof. Monti sucht Kraus (3) eine Reihe anf die ererbte Syphilis bezüglicher Fragen zu beantworten. Die Frequenz betrug in fiüfizehn Tahren 316 auf circa 50.000 bohandelte Kinter. d. i. 0.68 Pereent; in den angehen Jahren schwankt dic Talhl zwischen $0 \cdot 29$ und 1.49 Percent. Knaben und Mäldhen waren in grleicher Anzalhl vertreten. Dem Alter nach untielen dreiviertel der Falle (nach Abang der lecilive) anf die drei ersten Lebonsmonate. Dite liecilive troten za fatuz verschiedenen Ziten, meist aber erst nach dem vjerten Lebensmonate ein und betreffen nach der 
Statistik ungefähr die Hällte aller beubaditeten Fülle. Der Form nach war bei Ersterkrankungen das naculöse Syphilid las Häutiostr; ihm fulgten der Reihe nach das pajulöse, das maculu-pipulöse, das pestulöse syphilid und die Psoriasis. Tonter den locidiven übrwiegen bei weitem die Condylome. Auch was den 'Termin les ersten Auftretens der Sgphilis betrifft, ist das maculöse Syplilid an erster Stelle zu nempen; von 4.8 fiallen wurden 40 innerhalb res ersten Quirtales beobahteht. Milztumoren fanden sich in 20.36 Percent, Kingchonsypluilis (mit Einschluss der l'seutoparalysen) in 7.98 Pereent aller Erkranknngon. Lebersehwellung im tianzen nur vier Mal. Die Sterblichkeit betrug. suweit das puliklinische Material hierin Aufsehluss gibt, 43 Fiblle, von Reuen 21 in ersten Quirrtal des Lebens standen. Die häutigste 'l'udesursalde war Pneumonie and Bronchitis (zwöltnal), sowie Enterukatarrh und Entritis (zelumul). Yum Sabluss zeigt una

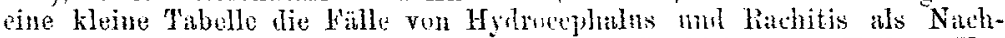
krankheiten der lates congenita: es fand sult: Rachitis in $\geq 4$ Fiallen. Hydrocephalus in 16 , beide zugleich in 7 Fallen. Weitere sihlussfolgermngen sind aus ler Statistik nicht gezugent.

'I'üplitz.

Muncorvo (4) liat sehun int Jaltre 188 s einen klinisehen Vortrag über die multiple Sklurese veröffentlicht. in wolchen or Arei Fille dieser seltenen Krankheit beschreibt. Schou dimals sprach er die Vemuthung ans, lass unter den iitiulugischen Momenten wohl anch die hereditare Syphilis ejo Rolle spielen hönue. Ein neuer (IV.) Fall veranlisst ihn nun, dies Moment noch nehx hervorzuheben. Ein dreijäriges Mäilehen. dessen Vater eingestand, an Syphilis gelitten zu haben, zeigte von cioburt an eine langdauernde Curyza, verseliedene Exantheme, sunst war sie bis zum Ende des dritten Jahres zwar schwächlich, aber gesund. Um diese Zeit fing sie an, sich völlig zu verändern; sic wurle reizbar, leftig, ungehorsam, der Gang unsicher, taumelud; Gegenstände, die sio in der Hand hielt, liess sie fallen nul hörte anf zu gelen. Wollte sie vhne Unterstätzung rehen, so brachen die Beine unter ihr zusiummen und sie setzte sich zur Eride. Eine zweimonatliche antisyplilitische Behandlung beseitigte alle diese Erscheinungen. Zweicinhalb Jahre darauf, während welcher Zeit sie angeblich vollkonmen gesund gowesen war. erkrankte sie unter denselben Erscheinungen von Nenem; Verfasser foum die grleichen Storungen des Ganges und der allgemeinen Stimmung. Than kimu alber häufiges Anfschrecken im Schlafe, störungen der Intelligenz nud der sprache, welehe letztere langsimn und scandirend geworden wir, und endlich ein ausgesprochenes Intentionszitten der Finde. Nacls einer kurzen fieberlaften Erkrankung (Euloourditis rhonumatial) trat cine sehnolle besserung aller nervösen Erseheinmugen ein; der Gings besserte sich. die beingstigenden Trïume versthwanden, die sprache wirde leichter. disi Zittern geringer. Unter energischer Behandlung nit Joikalinu abwechselni mit innerlicher und äusserlicher Anwendung von Quecksilber sing die besserung weiter vorwirts, und nach neun Munaten war bis anf geringes spuren des Trenors nichts Abnormes mehr nachzuweisen. Ein Jalle darant war die Heilung noch von Bestand. Aus dem Fehlen eines jellen anderen atiologischen Tromentes, aus den sicheren Anzeidhen roriungegingener Lues und aus dem Erfolg der specitischen Behamelung schlicsst Verfisser. dass es sich in der That hier nm eine syphilitische Getissverinderung gehandelt habe, welche das bild dor multiplen Herisklerese erzeugt liat. und fortert nut. bei den immerhin seltenen Fallen ron sklecuse in hindesalter die syjhilis als attiolugischen Fiketor nicht zu ïbersehen. Tüplitz.

In der Novembersitzung der pathulogischen Gescllschalt za Lumlun berichtet White (3) äber folgenden Full, als bewcis tiür dits Vorkommen 
ausgedehnter amyloider Entartung bei kindlicher congenitaler syphilis. Die Patientin war sieben Jahre alt, beile Eltern litten an Syphilis, sie selbst zeigte fast alle Zeichen der cungenitalen Lues. Der Leberrand war als harter runder Wulst oben über dem Dammbein kaum fühlbar, die Hilz reicht bis an den Nibul. Dor Unterlein war emptindlich, dats linke Auge zeigte die Erscheinungen der disseminirten Choroiditis and Neuritis optica. Die Drüsen der rechten Axilla wiren vergrössert und cin sehmerzhafter Knoten fand sich über deln Kopf der Tibia; der Urin war eiweisshaltig und dies brikehte die Diasnose anf Anyluidentartung. Unter sperifischer $\mathbf{B e -}$ hantlung erholte sich zunïchst Patientin etwas, erlag daun aber einem Anfall von acnter 'I'onsillitis. Die leber wog bei der Scetion 1830 Gramm, sie war hart unl stark gewölbt, mit cirrhotisch-fibrösen, radiär über die ganze Obertliche lantenden Einziehungen. An der Vurderfliche fand sich ein wallnussgresses Gmmma. lecber, die stark vergrösserte llile und die Nieren zeigten alle hochgradige Amyloidentartung. Auch Daimmlarm und Halsdrüsen zeigten Amyloid. Es funlen sich auf alte Peritunitis dentende Stringo, nirgenłs aber Spuren einer etwa uberstandenen Eiterung. In der Discussion worde anch von inderer sieite anf die grusse Seltenheit eines solchen Befundes autmerksam gemacht.

Arning.

Pedicini (6) thoilt dic auf syphilis beruhenden krankhaften Verinderungen der Placenta ein in chronische indurative Entzünilungsprocesse (Placentarsklerose) und in eigentliche Placentargummen. Erstere erscheinen in zwei Hauptgruppen, einer circumscripten oder nodulären nnd einer diffusen. - Bei der circumseripten vider knotentörmigen Placentarsklerose findet man das Gewebe der Placenta von gelblich-weissen Knitchen durchsetzt, die sich in die Masse der Cutyledonen einsenken. Anf Schnitten zeigen diese Kü̈tchen ein fibröses Aussehen, sie sind zum Theil compact, zum Theil bergen sie in ihrem Inneren kleine Höhlungen mit hämorrhagischen Inhalt. Je iilter der Process ist, unso resistenter und derber sind die Knütehen. Mitunter erscheint die uterine Oberfläche der Placenta vollkommen gesund, während sich an der fötalen unter dem hie und da getrübten und verdickten Choriun die erwïhnten knotenfürmigen Verdickungen in variabler Anzalıl vorfinden; mitunter ist anch das Umgekehrte der Fill. In anderen Fiillen beobachtet man an surgtältig angefertigten Schnitten, dass das Placentargewebe, speciell die einzelnen Zottenbündel and Zweigchen mit einander verschmolzen sind. wodann sie graulich-gelbe, verschieden consistente Massen bilden, die strahlenförmige Fortsatze in ihre Umgebung aussenden. Es ist lies cin jüngeres Stalium ler früher beschriebenen Erkrankung. Eine bisher noeh nicht beschriebene Form der circumscrijten Placentarsklerose ist dureh die Bildung zahlreicher iunserst kleiner Nortuli charakterisirt, dic bei ubertiachlicher Betrachtung eine diffuse tuburkelartige Infiltration vortïuschen können miliaritorme Intiltration. Es ist dies ein Process. der mit der Schwere der secundïrsyphilitisehen Manitustationen auf dor Hant und ant' de'n Schleimhïuten rleichen schritt häl. Aaf lie Frage, ob aus den in Rede stehenden Placentarveränderungen ein Schluss gezogen werlen könne. ob die Syphilis väterlichen oder mütterlichen Ursprungs sei, antwortet Verfasser, dass an vollkommen entwickelten Placenten dies absolut nicht möglich sei. Itediglich die Lamina cuticularis s. epithelialis externa der \%otten sei mïtterlichen Ursprungs; alles übrige sei eine Nasse von fötalen oler Chorionzotten und nur die dazwischen liegenden Rïume seien die Reprisentanten der miitterlichen vastonlïren Sinus. Sei das Virus mütterlichen Ursprunges, so könne es nur den Weg der geninnten sinus einhalten. und wem diese allein alterirt wärtn, nur dann könnte man mit Sicherheit von mütter- 
lichen Einfluss rerten mul somit liss Contugium des Eies unter ausschliessliche Abhängigkeit daron setzen. - Die liffusen Formen der chronischen Placentarskleroso kann man nach ihren gröberen anitomischen Charakteren auch diffuse chronische Placentitis nennen. Der Process ist flurch die Entwickelung eincr diffusen Bintegowebswaherung ausorotichnet, rie in verschiedenen, zum Theil strilhIenförmigen Zügen das Organ durehsetzt. und hat eine nicht zu verkennende Achnliehkeit mit jener Erkrankung der Leber, die unter dem Namen Hepatitis syphilitica lobatia bekant ist. Der Begimn des Prucesses lässt sich bereits mit freiem Auge erkennen. Er verbreitert sich von Rer Umgebungr der Gefïsse und ron diesen selbst. besomlers von den subchorialen Aesten, welche die dicksten unil häutig auch die am meisten alterirten sind. Die Verdickung ier Gefïsswiinde ist in vureschrittenen Starliun der Frkiankung selbst an len kleinsten Gefässen der Cotyledonen zu erkomnen. Kleine Zottenzweirchen fühlen sich wit: diunne schn̈̈re an nnd zeigen anf Querschnitten einen kleinen weissen Krejs mit einem contrilen sdiwarzen Pünktehen, hem Grfïslumen. Nio Hauptaweige der Nabelsehnurgefïsse, die sich auf der fïtalen Oberflithe der Placentil und unter dem Charion verschlïgoln, sind jene, an denen die sklerose den höchsten Grad erreicht; sie stellen ilicke, harte, geschliungrlte Strïnge dar. welche an jenen Stollen, wo sie sich an die dieotyledunïren Iappen ansetzen, eine directe Verbindung mit der erwälnten Bindegewebsneubilitung zeigen. Viele dieser Gefüsse sind auf weite Strecken thrmbosirt. Setzen sich die Thromben in die eigenen Nabelstranggefïsse fort. so ist der Tor des Fütus die nuausbleibliche Folge davon. Die Stenose der Nabelstranggefïsse ist bei len Frizchten syphilitischer Mütter ein häutiger Befund und nelsen den Verïnderungen der Intima ein sieheres Zeichen der Syphilis. Audurerseits lässt sich nicht lougnen, dass bei ansgespruchener Syphilis der Frucht und bei entsprechenden krinkhiften Veränderungen der Placenti die Umbilicalgefïsse auch vollkommen gesund befunten weriten können. - Viel dentlicher als die vorher beschriebenen PJacentarverandernugen documentiren die sogenannten franulome witer firmmen der Placentio ihre essentiell syphilitische Natur. Die Grösse der Placontargummen ist verschioden. Dio kleinen Gmmmen zeigen hiutigr contrale nekrotische Herde, ungeben von den thirateristischen rumben cramuliosen Elementen, die wegen ihrer cnomen Hinfällirkeit leicht zerfallen und die sugenamnte Zone kilsiger Erwoichung biliden. Ihre Entwickolung beobachtet min hanptsächlich an jungon Placenten. Dit kleinen grannlösen Horle sind mitunter diffus; diese Form lürtte auf das Confluiren nehrerer vinzclner Knötchen zurück»üühren sein. Verfusser machte ofturs die Beobathtungr. diss in der Decidua serotina die grossen Zellen durch eine parenclymatiose Degrneration oder durch eine nekrutische Colliguation zerstört werden. Sie verlieren ihren Fern und zerfallen in eine kïsige Masse. Fs handelt sich da nicht un neoplastische Herde, vielmohr sind es die Deeiduazellen selbst. die, ohne Zweifel in Folge von Ernahrungsstörungen, deren Natur nicht bekannt ist, auf liese Weise zu

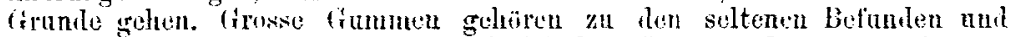
werlen hanptsiichlich in Ar syphilitischen Spatperiode angetroften. -

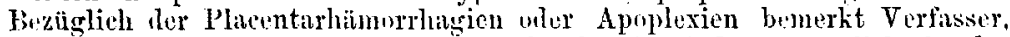
lass sie bei syphilitischen Weibern sehr hïufig sind, namentlich in der Periode der Virulenz. Dic Ansicht sei irrion, tass die sklerotisehen Knotehen und dio partiollen oder diffusen Indarationen eine Folire der Hïmorrhigrien seien. Dies anzundehen hoisse Ursache nnd Wirkung verwechwoln. Die gefilhrlichsten Blutungen scien jene, die in der Decidtua serotina, und zwar am häutigsten im dritten Schwangerschaltsmunate vorkummen. Ausser der grussen Zorreissbarkeit der Gefitse und ihrem 
beträchtlichen Volumen sei die gummöse Degeneration der Elemente der Decidua die Hauptursache der schweren Blutungen. Bei älteren Placenten werden die Hämorrhagien häufig dnrch Arteriosklerose bedingt, wohl auch durch fettige Entartung der Capillaren. - Die Unterbrechung der Gravidität bei syphilitischen Weibern dart, wie Pedicini betont, nicht für alle Fälle als Resultat pathologischer Processe der Placenta angesehen werden: denn, wenn auch in den meisten Fällen der Abortus in Folge Ruptur der Utero-Placentargefässe erfolgt, kann die syphilitische Infection auch direct auf den Fötus iubertragen werden, welcher dann abstirbt und vor der Zeit ausgetrieben wird. Oedem der Zotten, cystoides Jyxom, fettige Degeneration und ausgebreitete Verkalkungen des Zottenparenchyms, Hydrops placentaris u. s. w. können die von Syphilis abhängigen Placentarveränderungen begleiten, haben jedoch mit der Placentarsyphilis nichts zu schaffen.

Dornig.

\section{Therapie der Syphilis.}

1. Barduzzi D. Del salolo nella terapia locale delle malattie veneree $\theta$ cutanee. - Giorn. ital. delle mal. ven. e della pelle 1887, 4 .

2. Verneuil. Sur le traitement de la syphilis. - Bullet. gén. de thér., 30. October 1887.

3. Galliot. Nouveaux faits en faveur de l'emploi des injections hypodermiques de vaseline médécinale avec calomel ou oxyde jaune dans le traitement de la syphilis. - La semaine médicale 1887, Nr. 50.

4. Morrow A. An Appreciation of the modern method of treating syphilis by hypodermic injections. - New-York, Acad. of Medicine, 6. October 1887. Med. Rec. 884, 1887.

5. Wachsner. Die Wirkung des elektrischen Inductionsstromes auf subcutane Einspritzungen. - Deutsche med. Wochenschr. 1887, Nr. b̈1, pag. 1099.

6. v. Watraszewski. Ueber Behandlung der Syphilis mit Injectionen unlöslicher Quecksilbersalze. - Monatsh. f. prakt. Derm. 1887, Nr. 22, pag. 989.

7. Garnett A. S. A few practical observations upon the treatment of the late neoplasms of syphilis. - Journ. of cut. and gen.-urin. dis. 1887, Nr. 8, pag. 307.

8. Stefanoff. Dry Hot-tir Baths for syphilitic patients. - The Lancet, 25. Juni 1887 .

9. Guinon. Hystérie Mercurielle - Gaz. mér. de Paris 48. 1887.

10. Morrow A. Idiosyncrasy as affecting the specific treatment of syphilis. - Journ. of cut. and gen.-urin. dis. 1887, Nr. 8, pag. 289.

Barduzzi (1) rihnt in einer vorläufigen Mittheilung die Wirksamkeit des Salols als eines dex werthvollsten antiseptischen Mittel bei der Behandlung der venerischen Geschwüre, der ulcerösen srphilile u. s. w. Das Salol spalte sich nicht nur in Dünndarm, wie Nencki gezeigt. bat, sondern anch dann. wenn es mit lebenden Geweben in Berührung kummt, in Salicylsäure uni in Phenol. Darin allein schon liege die Bürgschaft für die therapeutische Wirksamkeit des Salols.

Dornig.

Die Grundsätze, welche Verneuil (2) über die Behandlung der Lues resumirt, bringen nichts Neues, sondern im Wesentlichen nur ein kurzes Résumé seiner bereits früher (Soc. de Chir. 1867) ausgesprochenen Vorliebe einer sofortigen dauernden (zwei Jahre) $\mathrm{Hg}$-Behandlung in kleinen Dosen in der Form von Protojodur innerlich.

$\mathrm{L} \ddot{\mathrm{w} w} \mathrm{enh}$ ard t.

Vierteljahresschrift t. Dermatol. u. Syph. 1888. 
Galliot (3) berichtet über die ausserordentlich günstigen Resultate, welche er mit Injectionen von Calomel und Hydrargyrum oxydat. flavum, suspendirt in reinem Vaselinol (nach Balzer) an mehr als hundert Syphilitikern (mit 4ว̈0 Injcetionen) erhalten hat. Er hat beide Präparate zuerst in der Einzeldose von 0.15 , dann von 0.1 angewendet, beide mit ungefähr gleichem Erfolge, nur dass das Hydrargyrum oxyd. flavum, als das feinere Pulver die Canule weniger light verstopfe. Besonderen Werth legt der Verf. auf die Wahl der Injectionsstelle: er emptiehlt zwei Finger breit über dem Trochanter major und vier Finger breit hinter seinem Kopfe, an der Grenze des äussieren unil mittleren Drittels einer vom uberen Ende der Analfurche nach aussen gozogenen Hurizontalen, einzustechen, und sich diese Stelle, wenn mau die Injection im liegen macht, vorher bei aufrechter Stellung zu fixiren. Die heftigun schmerzen, welche bei manchen Patienten nach Injectionen an anderen Stullen auftreten, sollen hier immer ausbleiben; nur eine veringe Unberqumlichkeit (ngene") am dritten, oder nach stärkeren Bewtgungen am zweiten 'Tage, soll die Folge sein; cin im Ganzen unbelenteniles Intiltrat in subeutanen Gewebe besteht 8-10 Tage; einen Abscess hat der Verf. - bei peinlicher Innehaltung der antiseptischen Cautelen - nicht beobachtet. Zweimal bildete sich an der Einstichstelle cine "Hämatucele ${ }^{\star}$, d. $l_{1}$, eine geringe Ansammlung dickflüssigen Blutes divht unter der Haut, nach deren Entleerung keine Störung mehr eintrat. Galliot erklärt diese Erscheinung als auf einer Ruptur der in dem entzündlichen Knoten eingeschlossenen Gefässe beruhend; die Injection war bei diesen beilen Patienten uicht tief genug gemacht worden. Die curative Wirkung der Injectionscur tritt auch nach den Erfahrungen Galliot's sehr schuell und sicher ein; Salivation wurde - bei gleichzeitiger innerlicher Anwendung ron 4 Gr. Kal. chlor. pro die - besonders beim Quecksilberoxyd fast gar nicht beobachtet. Die Zahl der applicirten Injectionen betrug niemals unter drei; dieselben wurden in Zwischenräumen von je einer Woche vorgenommen; bei hartnäckigeren Formen wurde die Zahil der Einspritzungen gesteigert. Das casuistische Material, welches der Verfisser anführt, sull nur daza dienen, die Schnelligkeit der Wirkung der Injectionen zu demonstriren. In den Schlussbemerkungen werden mit Recht die ausserordentlichen Vurtheile dieser Methode für die Privat- wie die Hospitalpraxis herrorgehoben: die Abtheilung des Verf. in Brest ist jetzt leerer als je zuvor, weil die früher Monate lang dort behanlulten - hartnäckigen Furmen jetzt in wenigen Wochen zur Heilung kommen. Lie Frage der Recidive wird mit einigen Worten über die "Kraft der woissen Blutkürperchen" (in Anlehnung an Metschnik off) gestreift, olne dass der Eindruck, den der Verf. geliabt hat, dass die Recidive nach der neuen Behandlung länger ausbleibt, durch Thatsachen gestützt wird.

Jadassohn.

Nach ciner etwas breiten Einleitung uber Furtschritte in der Luesbehandlung bespricht Morrow (4) in seinem Vortrage eigentlich nur die subcutane Calomelbehandlung der Syphilis, und hier hauptsächlich oder fast allein die Methode durselben, welche die Franzosen üben und ihre Ansichten über dieselbe, wie sie uns genugsam bekannt sind, und wie sie längst in dentsehen Arbeiten ihre "Vorbestiitigung" viler Zurïckweisung gefunden haben. Sehr richtig wendet er sich gegen die in französischen Veröffentlichungen ständig wiedorkehrende Phrase, dass man mit 40 Centigramm Calomol oder 25 Centigram Bichlorid die Syphilis heilen könne, was wohl nie in Ernst gemeint ist. Stomatitiden, deren Vorkommen ihm bei seinem Besuche in Frankreich allgemein bestritten wurde, hat er selbst in zwei Fillen dort constatiren können. Sehr aufgefallen ist ihm und er- 
scheint ihm gewichtig, dass der Verdaunngstractus bei Injectionen des unlüslichen Salzes von mercuriellen Strirungen ständig rerschont schien. Man habe demnach bei dieser Methode der Behandlung nicht nur die Mïglichkeit, sondern die Sicherheit einer Einwirkung interner Roborantien und einer rationellen Diät, deren man bei interner Darreichung von $\mathrm{Hg}$ leicht verlustig gehe, und die sehr hoch anzuschlagen sei - und die in der That hoch anzuschlagen ist. Er schliesst: „Die subeutane Calomelmethode wird die üblichen Methoden (rorwiegend innere Medication) nie verdrängen." Sie bietet aber doch ein ausgezeichnetes Hilfsmittel bei Allgemeinerkrankungen der Verdauungsorgane und bei Idiosynkrasie derselben in gesunden Verhaltnissen gegen $H_{g}$; sie rerdient deshalb mehi Beachtung, als sie bis jetzt erfahren. In der anschliessenden Discussion empfiehlt Taylor mit Einschränkungen die subcutane Behandlung. Sturgis ebenso, erklärt sich aber mehr für Calomel als Sublimat, während Bulkley sich überhaupt gegen die Injectionscuren wendet. Als Einleitung der Discussion hatte Dr. Bronson berichtet, dass er mit Sublimat schlechte Erfahrungen gemacht habe, schlechtere mit Calomel. Auch in der Theorie könne er den subcutanen Injectionen seinen Beifall nicht bewilligen: ein Depositum für den Körper zu geben im Körper, um ron da aus eine Krankheit zu heilen, scheine ihm zu geschäftsmässig, um rationell und wissenschaftlich zu sein.“

Harttung.

Wachsner (5) empfiehlt nach subcutanen Injectionen die Injectionsstelle etwa vier bis fünf Minuten zu faradisiren und zwar durch Streichen mit der negativen Elektrode, während die positive Elektrode an einer beliebigen Stelle aufgesetzt wird. Hierdurch werden die darunter liegenden Muskeln zur Contraction gebracht und der sich contrahirende und wieder erschlaffende Muskel wirkt nach Art einer Saugpumpe und befördert die injicirte Flüssigkeit ron der Injectionsstelle fort, so dass keine Anhäufung derselben stattfindet. In Folge davon fehlen bei derartig gemachten Injectionen die Reactionserscheinungen, wie sich $\mathrm{Wachsner}$ bei mehr als tausend Injectionen mit Sublimat, Kampher, Arsenik und Ergotin überzeugen konnte. Einige Kranke hatten rorher Injectionen erhalten, die im Gegensatze zu den von Wachsner gemachten schmerzhaft waren. Einige Male unterliess er versuchsweise die Faradisirung, stets waren diese Injectionen schmerzhaft. Dreizehn Krankengeschichten über Fälle von Syphilis und Sublimatinjectionen und von Blutungen verschiedener Art mit Ergotininjectionen behandelt, sind beigefügt.

v. Watraszewski (6) hat mit einer Reihe verschiedener unlöslicher Quecksilbersalze therapeutische Versuche angestellt. Bei gleicher Menge des eingespritzten Medicaments steht die Wirkung im Allgemeinen im directen Verhältniss zu den in demselben enthaltenen Quecksilberpercenten. Die Calomelinjectionen haben entschieden die meiste Neigung, Abscesse hervorzurufen. Den stärksten Quecksilbergehalt haben die Oxyde, daher genügen von diesen auch die relativ kleinsten Mengen. Ganz besonders zufrieden war Watraszewski mit dem Hg. oxyd. flar, von welchem 4-6 Injectionen à $0.04-0.06$ in wöchentlichen Intervallen gemacht, in der Mehrzahl der Fälle sowohl von früher wie ron später Syphilis ausreichend sind, Bei der Injection muss die Glutialmusculatur vallig erschlafft sein, die Injectionsflüssigkeit muss ungefïhr Körpertemperatur haben, nach der Injection muss durch Druck auf die Einstichstelle das Eintreten von Flüssigkeit in den Stichcanal verhütet und durch rotirende Bewegnng der anfgelegten Hand (nicht Kneten oder Massiren) für Vertheilung der Flüssigkeit gesorgt werden. 
Garnett (7) empfiehlt dringend die energische Behandlung der Syphilis überhaupt und besonders der späten Stadien. Er gibt $3.5-60 \mathrm{Granm}$ Jodkalium täglich und hat gefunden, dass diese hohen Dosen oft besser vertragen werilen, als die niedrigen. Ausserdem empfiehlt er die Bäder von Hot springs. Zur Bestätigung werden zwei geheilte Fälle (Paralyse, Aphasie und geistige Schwäche) angeführt.

Lesser.

Stefan off (8) hat wieder einen leizbaren Kasten construirt, in dem der Patient als Vorbereitung zur Schwitzcur "gebacken * wird, wodurch die Haut zur Aufnahme spiiterer Quecksilberbehandlung wieder fähig gemacht werlen soll, nachdem die Syphilis auch noch auf $\mathrm{Hg}$ oder $\mathrm{J}$ reagirt hatte.

Guinon (9). Die Existenz hysterischer 7ustände im Ver]aufe chronischer Intoxicationen steht unzweifulhaft fest (Blei, Quecksilber, Alkohol und vielleicht auch Syphilis), aber die Bezielungen der Intoxicationen und ler Hysterie werden verschieden interpretirt; und es bleibt noch immer fraglich, ob die nervisen Störungen wirklich einer Quecksilbervergiftung des Nervensystems (Achard, Debove, Bucquois) zugeschrieben werden müssen, oder sich unter dem Einflusse des (iittes als Gelegenheits-Ursache bei priilisponirten Individuen die Psrchopathie entwickelt (Isetutte, Potin, Charcot). Diese Controverse ist analog der Frage iiber die Tabes (Charcot contra Erb und Leyden). Guinon bringt nun eine genane Krankengeschichte von einem Spiegelarbeiter, in der die Hysterie allein das directe Resultat der Intoxication ist, kurz, dass ohne. Prïdisposition eine rein toxische, symptomatische Psychopathie durch $\mathrm{Hg}$ hervorgerufen ist.

Lïwenhardt.

Morrow (10) nnterscheidet drei Arten von Abweichung. Welche die Wirkung der zur Behandlung der Syphilis gebrauchten Specifica (Quecksilber, Jod) von der gewöhnlichen Art ler Wirkung haben kann: erstens ungewöhnliche Empfindlichkeit für die pliysiolngischen oder toxischen Wirkungen der Mittel. zweitens Hervorrufung unangenehmer Nebenerscheinungen auf Haut oder Schleimhäuten oder in anderen Organen, drittens Unempfindlichkeit des Organismus gegenüber der curativen Wirkung. Ausbleiben derselben. Bei grosser Empfindlichkeit gegen Quecksilber hilft es nichts, die Dosis des Nittels zu verringern, denn es handelt sich um eine Idiosynkrasie und der Organismus reagirt auch auf die kleinsten Quantitiiten. Wührend die einfacheren Joderuptionen keine Contraindication für Weitergebrauch des Mittels abgeben, steht es anders mit den schweren Fällen von Joderuptionen. Morrow führt die Krankengeschichten zweier solcher Falle an. Bei dem einen traten um ein syphilitisches Geschwür und auch an anleren Stellen in Folge des Jodgebrauches starke Schwellungen auf, die in Erweichung übergingen und grosse Aehnlichkeit mit syphilitischen Eruptionen hatten. Gleichzeitig stellten sich Schwilche, Schlaflosigkeit, starke Kopfschmerzen und heftige Schleimhautkatarrhe ein. In diesen Fillen muss man von der specifischen Behandlung absehen und neben allgemeiner tonisirender Behandlung ist besonders sorgfïltige Incaltherapitam alatze. Morrow empfiehlt bei stark eiternden syphilitischen Geschwïren besonders das Wasserstoffsuperoxyd. In Fïllen, wo die Wirkung der specifica eine abnorm geringe ist. wird man weniger nach. Surrogaten für jene Mittel zu suchen haben, als die Darreichnngsweisen der Medicamente zu rerbessern und zu vervollkommnen. Schliesslich warnt Morrow dringend vor jedem Schematismus bei der Syphilisbehandlung.

Lesser. 